\title{
Objetivos de Desarrollo Sustentable y funciones sustantivas en las Instituciones de Educación Superior
}

\begin{abstract}
Sustainable Development Goals and the main functions in Higher
\end{abstract}
Education Institutions

\section{Volumen 21, Número 3}

Setiembre - Diciembre

pp. 1-34

\author{
Julia Guadalupe García-Arce \\ Carlos Alberto Pérez-Ramírez \\ Blanca Estela Gutiérrez Barba
}

Citar este documento según modelo APA

García-Arce, Julia Guadalupe., Pérez-Ramírez, Carlos Alberto. y Gutiérrez Barba, Blanca Estela. (2021). Objetivos de Desarrollo Sustentable y funciones sustantivas en las Instituciones de Educación Superior. Revista Actualidades Investigativas en Educación, 21(3), 1-34. Doi. 10.15517/aie.v21i3.48160 


\title{
Objetivos de Desarrollo Sustentable y funciones sustantivas en las Instituciones de Educación Superior \\ Sustainable Development Goals and the main functions in Higher Education Institutions
}

\author{
Julia Guadalupe García-Arce ${ }^{1}$ \\ Carlos Alberto Pérez-Ramírez ${ }^{2}$ \\ Blanca Estela Gutiérrez Barba ${ }^{3}$
}

\begin{abstract}
Resumen: Los Objetivos de Desarrollo Sustentable (ODS) constituyen un marco para poder cumplir con los propósitos de la sustentabilidad en sus múltiples dimensiones sociales, económicas y ambientales. Por cuanto, las Instituciones de Educación Superior (IES) pueden ser consideradas como un actor social determinante para impulsar su cumplimiento. El presente artículo tiene como objetivo sintetizar criterios para el análisis de los ODS a partir de cuatro funciones sustantivas de la actividad universitaria: gestión institucional, prácticas y cultura ambiental de la universidad; educación y aprendizaje; investigación; y liderazgo social. Para ello, se llevó a cabo un análisis hermenéutico durante el periodo comprendido de enero a junio de 2020, en el que los productos obtenidos fueron ocho marcos analíticos y referenciales de diversas instituciones tanto mexicanas como internacionales. En este análisis se consiguió como resultado la coincidencia de 32 criterios clasificados de acuerdo con las funciones sustantivas de las IES, lo que permitirá comprender los alcances y limitaciones de las IES para el cumplimiento de Ios ODS y el impulso de la sustentabilidad. De manera preliminar, a pesar de que no se tiene una comprobación in situ se puede concluir que las IES, a través de las funciones sustantivas, pueden facilitar los ODS y la dimensión ambiental de la sustentabilidad.
\end{abstract}

Palabras clave: desarrollo sostenible, gestión educacional, desarrollo humano, enseñanza superior.

Abstract: The Sustainable Development Goals (SDGs) establish a framework to be able to fulfil the purposes of sustainability in its multiple social, economic, and environmental dimensions. While the Higher Education Institutions (HEls), can be considered as a determinant social actor to support their fulfilment. The aim of this article proposes a compilation of criteria for the analysis of the SDGs based on four main functions of university activity: institutional management, environmental and culture university practices; education and learning; research; and social leadership. For this a literature review was conducted during the period January to June 2020, in which the outputs were eight analytical and reference frameworks of various institutions at the international level and in Mexico has been carried out, which resulted in the coincidence of 32 criteria classified according to the main functions of the HEls; which allowed the elaboration of word clouds to determine the key elements for indicators, thus also allowing for an understanding of the achievements and limitations of the HEls for the fulfilment of the SDGs and the promotion of sustainability. Preliminarily, although there is no in situ verification, it can be concluded that HEls can facilitate the SDGs and the environmental dimension of sustainability through their substantive functions.

Keywords: sustainability, education management, human development, higher education.

\footnotetext{
1 Universidad Autónoma del Estado de México, Ciudad de México, México. Doctorado en Ciencias Ambientales. Dirección electrónica: jggarciaa001@alumno.uaemex.mx Orcid https://orcid.org/00000002-6028-0978.

2 Universidad Autónoma del Estado de México, Ciudad de México, México. Doctor en Ciencias Ambientales. Dirección electrónica: caperezr@uaemex.mx Orcid http://orcid.org/0000-0002-8074-2391

3 Instituto Politécnico Nacional, Ciudad de México, México. Doctora en Educación y Doctora en Biología. Dirección electrónica: bgutierrezb@ipn.mx Orcid https://orcid.org/0000-0002-0175-1899
}

Artículo recibido: 18 de noviembre, 2020

Enviado a corrección: 03 de marzo, 2021

Aprobado: 28 de junio, 2021 


\section{Introducción}

Desde la definición de sustentabilidad, en el Informe Brundtland de 1987, se reconocen los problemas ambientales que generan degradación del entorno físico y la necesidad de alcanzar un equilibrio en la naturaleza, sociedad, economía, política, cultura e incluso respecto a los avances tecnológicos; para ello, se deben que desarrollar diversas estrategias que impulsen el crecimiento económico y social, aprovechando los bienes naturales tanto renovables como no renovables de manera adecuada. Por lo que para 2015 se desarrollan los Objetivos de Desarrollo Sustentable (ODS), con la pretensión de establecer metas que ayuden a cumplir la sustentabilidad de manera eficiente en donde se puede considerar a la educación como una pieza loable para lograrlos.

De esta forma, la educación es un ODS y a la vez, una estrategia esencial para hacer consciente a la sociedad, con el objetivo de preservar la naturaleza y generar propuestas que ayuden a la población a satisfacer sus necesidades y a mejorar su calidad de vida. En particular, desde de la Educación Superior se pueden formular dichas propuestas, que involucren a diversos sectores de la población para el impulso de la sustentabilidad. Las Instituciones de Educación Superior (IES) desarrollan sus propuestas a partir de funciones sustantivas, que son un eje rector para cumplir con una filosofía institucional específica para cada IES y miden los alcances y limitaciones de su quehacer como agentes de cambio dentro de la sociedad.

Si bien se han desarrollado diversos trabajos previos que destacan proyectos para la evaluación de la sustentabilidad en las IES, se considera que los siguientes documentos son relevantes, pues son producto de trabajo colegiado entre Instituciones y organizaciones gubernamentales y no gubernamentales que, desde un punto de vista crítico, generan estrategias para poder lograr la sustentabilidad. Por lo tanto, destacan, a nivel internacional, la Organización de las Naciones Unidas para la Educación, la Ciencia y la Cultura (UNESCO, por sus siglas en inglés), que desarrolló la Declaración Mundial sobre la Educación Superior, basada en los Derechos Humanos, y que permea su incidencia en 17 artículos (UNESCO,1998). El Programa de las Naciones Unidas para el Medio Ambiente (UNEP, por sus siglas en inglés) crea un manual denominado Toolkit 2.0, que está centrado en la gestión ambiental de las IES (UNEP, 2014). El Grupo de trabajo sobre Evaluación de la Sostenibilidad Universitaria (GESU) y la Red de Universidades Españolas realizan un diagnóstico de la sostenibilidad Ambiental en universidades españolas, en el que se observa el cumplimiento de los ODS en España (Conferencia de Rectores de las Universidades Españolas [CRUE], 2018). 
En América latina, la Alianza de Redes Iberoamericanas de Universidades por la Sustentabilidad y el Ambiente (ARIUSA) formuló un documento denominado proyecto RISU, que crea criterios para la sustentabilidad para universidades de la región (ARIUSA, 2014).

En México, la Secretaría de Educación Pública (SEP), a través del Sistema Nacional de Información Estadística Educativa (SNIE), crea una base de datos para las IE de todos los niveles, la cual se conoce como Formato 911, que mide aspectos cuantitativos de las instituciones (SEP, 2020). En el año 2000, la Asociación Nacional de Universidades e Instituciones de Educación Superior (ANUIES) propone el Plan de Acción para el Desarrollo Sustentable en las Instituciones de Educación Superior, que promueve la implementación de acciones para la solucionar problemas ambientales (ANUIES, 2000). El Consorcio Mexicano de Programas Ambientales Universitarios para el Desarrollo Sustentable (COMPLEXUS) establece parámetros para medir la contribución de las IES a la sustentabilidad (COMPLEXUS, 2013).

A pesar de lo anterior no se han encontrado estudios que permitan analizar los ODS desde las funciones sustantivas en las IES en México ni a nivel internacional.

Por lo tanto, este trabajo tiene como objetivo sintetizar los criterios para el análisis de los ODS a partir de las funciones sustantivas de la actividad universitaria (gestión institucional, educación y aprendizaje, investigación y liderazgo social), a fin de reconocer la importancia de las IES para el cumplimiento de los ODS.

\section{Referente teórico}

\subsection{Objetivos de Desarrollo Sustentable}

Los ODS tienen sus inicios en la Conferencia de las Naciones Unidas sobre el Desarrollo Sostenible de Río de Janeiro en 2012. Sin embargo, comenzaron a aplicarse en 2015 para dar continuidad a los Objetivos de Desarrollo del Milenio (ODM) en el que se tiene como eje rector de la Agenda 2030 (Programa de las Naciones Unidas para el Desarrollo [PNUD], 2020), la cual surge como un plan de acción hacia la sustentabilidad para todas las naciones miembros de la ONU (Lange, Filho, Londero y Sapper, 2019).

Los ODS están conformados por 17 objetivos, 169 metas y 232 indicadores, que hacen referencia a la pobreza, el hambre cero, la salud y al bienestar, la educación de calidad, la igualdad de género, el agua limpia y el saneamiento, la energía asequible y no contaminante, el trabajo decente y el crecimiento económico, la industria, la innovación e infraestructura, la reducción de las desigualdades, las ciudades y las comunidades sustentables, la producción 
y consumo responsables, las acciones por el clima, la vida submarina, la vida de ecosistemas terrestres, la paz, la justica y las instituciones sólidas, y las alianzas para lograr los objetivos (PNUD, 2020).

Los ODS tienen una intervención global al estar presentes dentro de los 193 países adscritos a la Organización de las Naciones Unidades (ONU); sin embargo, el nivel de inmersión de los 17 ODS corresponde a los objetivos que cada nación tiene como meta y su compromiso con la sustentabilidad (Lange et al., 2019; Mohamed y Noguchi, 2019), por lo que las metas y los indicadores propuestos son opcionales para cada uno.

En este sentido, México contempla 169 de los 232 indicadores, en los que intervienen la Secretaria de Bienestar (BIENESTAR), la Secretaría de Agricultura y Desarrollo Rural (SADER), la Secretaría de Salud (SS), la Secretaría de Educación Pública (SEP), el Instituto Nacional de las Mujeres (INMUJERES), la Secretaría de Medio Ambiente y Recursos Naturales (SEMARNAT), la Secretaría de Energía (SENER), la Secretaría de Hacienda y Crédito Público (SHCP), la Secretaría de Economía (SE), la Secretaría del Trabajo y Previsión Social (STPS), la Secretaría de Desarrollo Agrario, Territorial y Urbano (SEDATU), la Secretaría de Gobernación (SEGOB), la Agencia Mexicana de Cooperación Internacional para el Desarrollo (AMEXCID), el Consejo Nacional de Evaluación de la Política de Desarrollo Social (CONEVAL), el Consejo Nacional de Población (CONAPO), el Instituto Federal de Telecomunicaciones (IFT), el Banco de México (BANXICO), el Instituto Nacional de Estadística y Geografía (INEGI), y el Consejo Nacional de Ciencia y Tecnología (CONACYT).

Además, para monitorear el avance de cumplimiento de los ODS, México cuenta con un Comité Técnico Especializado de los Objetivos de Desarrollo Sostenible (CTEODS) y una Comisión para el Cumplimiento de la Agenda 2030, la cual da seguimiento a las metas acordadas.

\subsection{Funciones Sustantivas de la actividad universitaria}

Las Instituciones de Educación Superior (IES) tienen un papel fundamental como forjadoras de seres humanos comprometidos con el medio ambiente, e interesados en mejorar su calidad de vida, a través de los preceptos de la sustentabilidad. Tal es el interés de las IES por la sustentabilidad, que han propuesto diversos documentos que señalan el vínculo entre la educación superior y ésta. Wright (2002) señala que la Declaración de Talloires de 1990, es la primera declaración universitaria que vincula la sustentabilidad y la educación superior, posteriormente se lleva a cabo la Declaración de Halifax en 1991, la Declaración de 
Copernicus en 1994, la Declaración de Tesalónica en 1997, la Declaración de Lüneburg en 2001, que es considerada la declaración más importante respecto a la Educación para el Desarrollo Sustentable (EDS), pues promueve la creación de una Agenda XXI para las universidades (Ull, Martínez, Pinero y Aznar, 2010), la Declaración de Abuja sobre la sustentabilidad en África: El papel de la educación superior en la sustentabilidad en 2009, entre otras (Fihlo, 2011; Holm, Sammalisto, y Vourisalo, 2015; Lozano et.al., 2015; ZapataGonzález, Quinceno-Hoyos, y Tabares-Hidalgo, 2016).

Pese a los planteamientos anteriores, no todas las IES han adoptado, como una de sus funciones sustantivas, criterios o indicadores, el cuidado ambiental ni la sustentabilidad. En el caso de México, se han realizado esfuerzos para que las IES tomen en cuenta a la sustentabilidad dentro de su política institucional, tal es el caso del Plan de Acción para el Desarrollo Sustentable en las IES que, de la mano con la ANUIES y el Centro de Capacitación para el Desarrollo Sustentable (CECADESU), han logrado el registro de 35 planes institucionales (Gutiérrez-Barba y Martínez-Rodríguez, 2010; Martínez y González-Gaudiano, 2015) de las 3762 IES públicas existentes en el país (OECD, 2019).

Las IES soportan su quehacer universitario en funciones sustantivas que fungen como guía para el desarrollo de sus actividades, características y requisitos para coordinar de una manera efectiva su filosofía institucional y la responsabilidad con la sociedad.

Tradicionalmente son tres funciones sustantivas de las IES: la docencia, la investigación y la difusión de la cultura (Arechavala, 2011; Avilés, 2009; Fabre, 2005; González y Ochoa, 2016; Guzmán, 2014). Sin embargo, la Red de Soluciones de Desarrollo Sostenible (SDNS, por sus siglas en inglés, 2017), propone una guía que aborda los ODS y su relación con las IES, en el cual se destacan cuatro funciones principales de la actividad universitaria:

- Gestión institucional, prácticas y cultura ambiental de la universidad: se pretende que la gestión en las IES vaya acorde con los ODS para cumplir con las acciones propuestas dentro de su filosofía institucional de todas las áreas que componen la institución. En este sentido, las IES pueden crear estrategias, políticas, planes e indicadores para incorporar los ODS (SDSN, 2017). Los procesos anteriores deben considerar una evaluación acerca de la docencia, la investigación, extensión y vinculación, en el que los resultados se consideren como estrategias para mejorar el desempeño institucional (González y Ochoa, 2016).

- Educación-aprendizaje: La SDSN (2017) considera la educación como aquella herramienta que sirve para lograr la sustentabilidad, el brindar una educación basada en 
competencias, en el que se empodere a las personas jóvenes y sobre todo que se le brinden las herramientas necesarias para enfrentarse al campo laboral. Además, se debe capacitar a los profesores y las profesoras para que cubran las necesidades de la sociedad, con el propósito de dar solución a problemas reales (Figueroa, Gilio y Gutiérrez, 2008; Vallaeys, 2006). Este rubro se ve influenciado específicamente por el ODS 4, en el que se pretende dotar al estudiantado de conocimiento, habilidades y motivación para comprender los ODS, empoderar y movilizar a la juventud, proporcionar formación académica o vocacional para implementar soluciones a los ODS, mejorar las oportunidades para el desarrollo profesional y de estudiantes, entre otros.

- Investigación: Dentro de este apartado se considera realizar una investigación inter y transdisciplinaria, realizar innovación tecnológica y de conocimiento, crear redes de trabajo, entre otras, con el propósito de cumplir con los ODS a través de soluciones en relación con la sociedad y la sustentabilidad (SDSN, 2017).

- Liderazgo social: De acuerdo con Campoverde, Rosero, González, y Ortíz (2018), y con la SDSN (2017), el liderazgo se refiere a que haya un diálogo intersectorial para lograr un objetivo final, en el que se desarrolle un compromiso y colaboración entre la sociedad y la universidad. En este sentido, se busca que las IES que consideren tomar en cuenta esta función, sean un ejemplo para las demás instituciones.

\section{Metodología}

\subsection{Enfoque}

Para desarrollar esta investigación, se utilizó un enfoque cualitativo en el que se examinaron documentos de libre acceso publicados y reconocidos a nivel internacional. Este proceso se realizó en el periodo comprendido de enero a junio de 2020. La búsqueda arrojó publicaciones de universidades a partir del año 1987, que es cuando toma mayor relevancia el término de sustentabilidad. No obstante, se optó por aquellos documentos avalados por un conjunto de redes colegiadas de trabajo a nivel nacional e internacional, lo que dio como resultado -sin demeritar a los demás documentos- ocho organismos/instituciones que han creado criterios para valorar la sustentabilidad en las IES.

Los criterios fueron concebidos mediante un análisis hermenéutico o cualitativo de la información con el software Atlas.ti $®$ versión 8.4. El término hermenéutica se define como el análisis e interpretación de documentos de acuerdo con la experiencia de los autores (Arráez, Calles, y Moreno de Tovar, 2006). De esta forma, fue posible identificar las características de 
la sustentabilidad que deben de estar presentes en las IES. Estos criterios se clasificaron dentro de las cuatro funciones sustantivas de la educación superior y se relacionaron con los 17 ODS para conocer si estos pueden lograrse dentro de las IES con la menor incidencia de actores externos a esta. En resumen, las categorías de análisis que guían este estudio son los ODS y las funciones sustantivas de las IES.

\subsection{Unidades de análisis}

Se tomó en cuenta los documentos para la evaluación de la sustentabilidad en las IES, los propuestos por ANUIES (2000), ARIUSA (2014), COMPLEXUS (2013), CRUE (2018), ONU (2015), SEP (2020), UNEP (2014) y UNESCO (1998) con la finalidad de identificar criterios de análisis para medir la sustentabilidad en IES; los documentos de las instituciones anteriores fueron seleccionados utilizando las palabras clave de: educación, sustentabilidad y universidades en los buscadores de Google académico, y en las bases de datos Elsevier, Redalyc y Scielo del año 1987 a 2020, debido a que encontró un número considerable de revistas científicas relacionadas con la educación tanto en español como en inglés. Estos documentos fueron elegidos por su relevancia internacional y regional (casos exclusivos en México), además por los alcances que han tenido con respecto a la factibilidad de las propuestas, y porque han sido referentes como antecedentes del vínculo entre sustentabilidad y educación superior.

\subsection{Técnicas de recolección y procesamiento de análisis}

Al margen de lo anterior, determinar si un documento cumplía con cierto criterio se recurrió a la fuente principal para establecer su injerencia en cada una de las funciones sustantivas; es decir, primero se leyeron y codificaron los documentos, se seleccionaron las características principales de cada documento, denominándolo como "criterio", después se crearon las categorías de análisis con base en las funciones sustantivas (Gestión institucional, educación y aprendizaje, investigación, y liderazgo social). Mientras que, para el papel de los ODS dentro de los criterios, se consideraron algunos de los 17 ODS que tienen una relación para cumplir con el objetivo; y para la dimensión de sustentabilidad se utilizaron las tres más conocidas (social, económico y ambiental) 


\subsection{Procesamiento de análisis}

Para la elaboración de criterios; primero se hizo una lectura minuciosa del documento base con el apoyo del software Atlas.ti ${ }^{\circledR}$ versión 8.4, para poder identificar las características que eran fundamentales, estas características se obtuvieron con el uso de frecuencia de palabras o indicadores que merecen ser parte de una investigación con mayor profundidad. Después, cada criterio o palabra se ubicó de acuerdo con el ODS, función sustantiva y dimensión de la sustentabilidad con la que concordaba. Finalmente, se aglutinaron los criterios y se ubicaron coincidencias entre conceptos para reducir el número de criterios.

Posterior a este proceso, se ubicaron los documentos y criterios finales para determinar cuál de ellos era el que tenía mayor cumplimiento.

\section{Resultados}

Se realizó el análisis hermenéutico de los documentos de las instituciones de UNESCO (1998), ARIUSA (2014), UNEP (2014), ONU (2015) y CRUE (2018), ANUIES (2000), COMPLEXUS (2013), SEP (2020), con el software Atlas.ti $®$ versión 8.4, lo cual arrojó la siguiente información:

\subsection{Organización de las Naciones Unidas para la Educación, la Ciencia y la Cultura (UNESCO)}

Para el documento base de la UNESCO, se tomó en cuenta a la Declaración Mundial sobre la Educación Superior (DMES), que se señala a través de 17 artículos que la Educación Superior debe fomentar los preceptos de una cultura de paz (UNESCO, 1998). Al analizar estos artículos dentro del contexto internacional actual, se puede plantear una relación entre los artículos de la DMES y los ODS, los criterios que toman en cuenta, la función sustantiva a la que se puede alinear y la dimensión de la sustentabilidad a la que pertenece (Ver tabla 1): 
Tabla 1

Análisis del vínculo entre la Declaración Mundial sobre la Educación Superior (1998) y los ODS (2015), considerando artículos de la DMES, ODS, criterios, función sustantiva y dimensión de la sustentabilidad.

\begin{tabular}{|c|c|c|c|c|}
\hline DMES & ODS & Criterios & $\begin{array}{l}\text { Función } \\
\text { sustantiva }\end{array}$ & $\begin{array}{l}\text { Dimensión de la } \\
\text { sustentabilidad }\end{array}$ \\
\hline 1 & $4,8,9$ & $\begin{array}{l}\text { Educar, formar y realizar } \\
\text { investigaciones para contribuir al } \\
\text { desarrollo sostenible. }\end{array}$ & $\begin{array}{l}\text { Educación y } \\
\text { Aprendizaje }\end{array}$ & Social, Ambiental \\
\hline 2 & 4,10 & $\begin{array}{l}\text { Ética, autonomía, responsabilidad } \\
\text { y prospectiva. }\end{array}$ & $\begin{array}{l}\text { Gestión } \\
\text { institucional } \\
\text { Educación y }\end{array}$ & Social \\
\hline 3 & $1,4,5,10$ & Igualdad de acceso. & $\begin{array}{l}\text { Aprendizaje } \\
\text { Gestión } \\
\text { institucional }\end{array}$ & Social \\
\hline 4 & $4,5,10$ & $\begin{array}{l}\text { Participación y promoción del } \\
\text { acceso de las mujeres. }\end{array}$ & $\begin{array}{l}\text { Gestión } \\
\text { institucional }\end{array}$ & Social \\
\hline 5 & 4,9 & $\begin{array}{l}\text { Difusión de investigación, la } \\
\text { innovación interdisciplinaria y } \\
\text { transdisciplinaria. }\end{array}$ & Investigación & Social \\
\hline 6 & 4,10 & $\begin{array}{l}\text { Pertinencia con respecto a } \\
\text { aspectos sociales y laborales. }\end{array}$ & Liderazgo social & $\begin{array}{l}\text { Social, } \\
\text { Económico }\end{array}$ \\
\hline 7 & $1,8,10$ & $\begin{array}{l}\text { Bolsa de trabajo adecuada las } \\
\text { necesidades laborales y sociales }\end{array}$ & Liderazgo social & $\begin{array}{l}\text { Social, } \\
\text { Económico }\end{array}$ \\
\hline 8 & 4,10 & $\begin{array}{l}\text { Diversificar los métodos de } \\
\text { enseñanza. }\end{array}$ & $\begin{array}{l}\text { Enseñanza y } \\
\text { Aprendizaje }\end{array}$ & Social \\
\hline 9 & 4,10 & $\begin{array}{l}\text { Desarrollar métodos educativos } \\
\text { innovadores y creativos. }\end{array}$ & $\begin{array}{l}\text { Enseñanza y } \\
\text { Aprendizaje }\end{array}$ & Social \\
\hline 10 & 4,10 & $\begin{array}{l}\text { Personal y estudiantes como } \\
\text { piezas fundamentales de la } \\
\text { educación superior. }\end{array}$ & $\begin{array}{l}\text { Enseñanza y } \\
\text { Aprendizaje }\end{array}$ & Social \\
\hline 11 & 4 & $\begin{array}{l}\text { Evaluación de la calidad de la } \\
\text { enseñanza. }\end{array}$ & $\begin{array}{l}\text { Gestión } \\
\text { institucional } \\
\text { Gestión }\end{array}$ & Social \\
\hline 12 & 4,9 & Enfrentar las nuevas tecnologías. & $\begin{array}{l}\text { institucional, } \\
\text { educación y } \\
\text { aprendizaje }\end{array}$ & Social \\
\hline 13 & $4,8,12,16$ & $\begin{array}{l}\text { Mejorar la gestión y financiamiento } \\
\text { de la Educación superior. }\end{array}$ & $\begin{array}{l}\text { Gestión } \\
\text { institucional }\end{array}$ & Económico \\
\hline 14 & 4,8 & $\begin{array}{l}\text { Financiamiento de recursos } \\
\text { privados y públicos. }\end{array}$ & $\begin{array}{l}\text { Gestión } \\
\text { institucional }\end{array}$ & Económico \\
\hline 15 & 4,16 & $\begin{array}{l}\text { Cooperación internacional en } \\
\text { cuanto a conocimientos. }\end{array}$ & Investigación & Social \\
\hline 16 & $4,8,16$ & Impedir la "fuga de cerebros". & $\begin{array}{l}\text { Investigación, } \\
\text { gestión } \\
\text { institucional }\end{array}$ & Social, económico \\
\hline 17 & 4,17 & Crear alianzas. & $\begin{array}{c}\text { Gestion } \\
\text { institucional, } \\
\text { investigación y } \\
\text { liderazqo social }\end{array}$ & Social \\
\hline
\end{tabular}

Fuente: Elaboración propia con base en la UNESCO (1998) 
Al margen de lo anterior, se considera que la DMES, contempla en su mayoría los aspectos de la función sustantiva de Gestión institucional, en segundo lugar, el de Educación y aprendizaje, en tercero con la investigación y por último con Liderazgo Social. Cabe resaltar que únicamente el artículo uno y el artículo 14 mencionan explícitamente al desarrollo sustentable como objetivo de estos; sin embargo, cada uno de los artículos tienen relación con la sustentabilidad. Además, los ODS que principalmente se pueden cumplir con esta Declaración son los objetivos 1 , 4, 5, 8, 9, 10,12, 16, y 17, y se considera que este documento principalmente evoca a la dimensión social de la sustentabilidad.

\subsection{Alianza de Redes Iberoamericanas de Universidades por la Sustentabilidad y el Ambiente (ARIUSA)}

ARIUSA surge en 2007, con el propósito de "desarrollar actividades de cooperación académica orientadas a la coordinación de eventos de interés común, la realización de proyectos colaborativos de investigación y el apoyo a la creación y fortalecimiento de programas de posgrados en ambiente y sustentabilidad" (Sáenz, 2017, p. 42). Producto de esta red de redes, se formula en 2013 el documento PROYECTORISU (Red de Indicadores de Sostenibilidad Universitaria), el cual contiene 114 indicadores clasificados en 11 rubros de sustentabilidad para universidades de la región (ARIUSA, 2014) en los que se puede entre ver una relación directa con los ODS (Ver Tabla 2). 
Tabla 2

Análisis del vínculo entre ProyectoRISU (2014) y ODS (2015) considerando indicadores de ProyectoRISU, ODS, criterios, función sustantiva y dimensión de la sustentabilidad.

\begin{tabular}{|c|c|c|c|c|}
\hline ProyectoRISU & ODS & Criterios & Función sustantiva & $\begin{array}{c}\text { Dimensión de la } \\
\text { sustentabilidad }\end{array}$ \\
\hline $\begin{array}{l}\text { Política de } \\
\text { sostenibilidad }\end{array}$ & 8 & $\begin{array}{l}\text { Impacto ambiental, } \\
\text { difusión, seguimiento } \\
\text { de políticas, trabajo } \\
\text { colegiado. }\end{array}$ & $\begin{array}{l}\text { Gestión institucional, } \\
\text { liderazgo social }\end{array}$ & Ambiental, social \\
\hline $\begin{array}{l}\text { Sensibilización y } \\
\text { participación }\end{array}$ & 4 & $\begin{array}{l}\text { Educación, } \\
\text { sensibilización, } \\
\text { eventos sustentables, } \\
\text { inclusión, curriculum. }\end{array}$ & $\begin{array}{l}\text { Educación y } \\
\text { aprendizaje }\end{array}$ & Social \\
\hline $\begin{array}{l}\text { Responsabilidad } \\
\text { socioambiental }\end{array}$ & $3,8,16$ & $\begin{array}{l}\text { Transparencia, } \\
\text { difusión, salud laboral, } \\
\text { prevención de riesgos, } \\
\text { redes de trabajo. }\end{array}$ & Gestión institucional & Social \\
\hline Docencia & 4 & $\begin{array}{l}\text { Contenido curricular, } \\
\text { actualización docente }\end{array}$ & $\begin{array}{l}\text { Educación y } \\
\text { aprendizaje }\end{array}$ & Social \\
\hline $\begin{array}{l}\text { Investigación y } \\
\text { transferencia }\end{array}$ & 4,9 & $\begin{array}{l}\text { Becas, actualización, } \\
\text { uso de tecnología. }\end{array}$ & $\begin{array}{l}\text { Educación y } \\
\text { aprendizaje }\end{array}$ & Social \\
\hline $\begin{array}{l}\text { Urbanismo y } \\
\text { biodiversidad }\end{array}$ & 9,11 & $\begin{array}{l}\text { Tecnología verde, } \\
\text { infraestructura } \\
\text { sustentable. }\end{array}$ & $\begin{array}{l}\text { Gestión institucional, } \\
\text { educación y } \\
\text { aprendizaje }\end{array}$ & Ambiental \\
\hline Energía & 4,7 & $\begin{array}{l}\text { Ahorro y eficiencia } \\
\text { energética. }\end{array}$ & $\begin{array}{l}\text { Gestión institucional, } \\
\text { educación y } \\
\text { aprendizaje }\end{array}$ & $\begin{array}{l}\text { Económico, } \\
\text { ambiental }\end{array}$ \\
\hline Agua & 4,6 & $\begin{array}{l}\text { Ahorro y eficiencia en la } \\
\text { gestión del agua. }\end{array}$ & $\begin{array}{c}\text { Gestión institucional, } \\
\text { educación y } \\
\text { aprendizaje }\end{array}$ & $\begin{array}{l}\text { Económico, } \\
\text { ambiental }\end{array}$ \\
\hline Movilidad & 11 & $\begin{array}{l}\text { Transporte } \\
\text { sustentable. }\end{array}$ & $\begin{array}{c}\text { Gestión institucional, } \\
\text { educación y } \\
\text { aprendizaje }\end{array}$ & $\begin{array}{l}\text { Económico, } \\
\text { ambiental }\end{array}$ \\
\hline Residuos & 11,12 & $\begin{array}{l}\text { Colecta, selección y } \\
\text { manejo adecuado de } \\
\text { residuos. }\end{array}$ & $\begin{array}{c}\text { Gestión institucional, } \\
\text { educación y } \\
\text { aprendizaje }\end{array}$ & $\begin{array}{l}\text { Económico, } \\
\text { ambiental }\end{array}$ \\
\hline $\begin{array}{l}\text { Contaminación } \\
\text { responsable }\end{array}$ & 12 & $\begin{array}{ll}\text { Ética } & \text { social, } \\
\text { contratación } & \\
\text { responsable } & \text { para } \\
\text { compras. } & \\
\end{array}$ & Gestión institucional & Social, ambiental \\
\hline
\end{tabular}

Fuente: Elaboración propia con base en ARIUSA (2014)

Analizando la tabla anterior, se puede observar que, de acuerdo con las funciones sustantivas de las IES, ProyectoRISU funge como facilitador de la función de gestión institucional, posteriormente de educación, luego la de investigación y por último el liderazgo social. En relación con los ODS, ProyectoRISU puede apoyar con los objetivos 3, 4, 6, 7 ,8, 11,12 y 16

Si bien ProyectoRISU fue elaborado por diversas Redes de IES, los ODS tienen una presencia significativa en este documento; sin embargo, se considera que contiene criterios 
que puede favorecer el desarrollo de prácticas sustentables dentro de las IES, pues la dimensión de sustentabilidad que se relaciona con este documento es el del ambiente, seguido del social y por último el económico.

\subsection{Programa de las Naciones Unidas para el Medio Ambiente (UNEP, por sus siglas en inglés)}

La UNEP es creada por la UNESCO para mejorar, promover y facilitar el uso de los recursos naturales para un desarrollo sostenible mundial adecuado. En 2014 crean un manual denominado Toolkit 2.0, que está centrado en la gestión ambiental de las IES. Tal y como lo menciona el objetivo de este manual, se enfoca principalmente a cubrir con la función sustantiva de la gestión institucional. Por lo tanto, se creería que los ODS tiene poca o nula cabida dentro de este Documento; sin embargo, los ODS (aunque pocos) pueden ayudar principalmente a los objetivos $3,4,6,7,8,9,11,12,13,14$ y 15 (Ver tabla 3)

Tabla 3

Análisis del vínculo entre Toolkit (2014) y ODS (2015) considerando indicadores de Toolkit, ODS, criterios, función sustantiva y dimensión de la sustentabilidad.

\begin{tabular}{|c|c|c|c|c|}
\hline Toolkit & ODS & Criterios & $\begin{array}{l}\text { Función } \\
\text { sustantiva }\end{array}$ & $\begin{array}{l}\text { Dimensión de la } \\
\text { sustentabilidad }\end{array}$ \\
\hline $\begin{array}{c}\text { Energía, } \\
\text { carbono y } \\
\text { cambio climático }\end{array}$ & 7,13 & $\begin{array}{l}\begin{array}{l}\text { Aminorar gases efecto } \\
\text { invernadero }\end{array} \\
\text { acondicionado, calefacción, } \\
\text { gas metano), energía } \\
\text { alternativa y renovable. }\end{array}$ & $\begin{array}{c}\text { Gestión } \\
\text { institucional }\end{array}$ & $\begin{array}{l}\text { Ambiental, } \\
\text { económico }\end{array}$ \\
\hline Agua & 6 & $\begin{array}{l}\text { Reusar y reciclar agua } \\
\text { potable y no potable, } \\
\text { conservación de agua. }\end{array}$ & $\begin{array}{c}\text { Gestión } \\
\text { institucional }\end{array}$ & $\begin{array}{c}\text { Ambiental, } \\
\text { económico, social }\end{array}$ \\
\hline Basura & 11,12 & $\begin{array}{l}\text { Minimizar residuos sólidos, } \\
\text { reparar y reusar y reciclar, } \\
\text { disposición final. }\end{array}$ & $\begin{array}{c}\text { Gestión } \\
\text { institucional }\end{array}$ & $\begin{array}{c}\text { Ambiental, } \\
\text { económico, social }\end{array}$ \\
\hline $\begin{array}{l}\text { Biodiversidad y } \\
\text { servicios } \\
\text { ecosistémicos }\end{array}$ & $\begin{array}{c}13 \\
14,15\end{array}$ & $\begin{array}{l}\text { Huertos, azoteas y muros } \\
\text { verdes, incrementar la } \\
\text { vegetación. }\end{array}$ & $\begin{array}{c}\text { Gestión } \\
\text { institucional }\end{array}$ & Ambiental, social \\
\hline $\begin{array}{l}\text { Planeación, } \\
\text { diseño y } \\
\text { desarrollo }\end{array}$ & 9 & $\begin{array}{l}\text { Optimizar espacios, } \\
\text { construcciones } \\
\text { sustentables, construcción } \\
\text { inteligente. }\end{array}$ & $\begin{array}{c}\text { Gestión } \\
\text { institucional }\end{array}$ & Ambiental \\
\hline Mantenimiento & 11 & $\begin{array}{l}\text { Normas ISO, } \\
\text { responsabilidad social } \\
\text { corporativa, planes de } \\
\text { acción, certificaciones. }\end{array}$ & $\begin{array}{c}\text { Gestión } \\
\text { institucional }\end{array}$ & Ambiental \\
\hline Oficinas verdes & 7 & $\begin{array}{l}\begin{array}{l}\text { Energía, agua, basura, } \\
\text { tecnología, } \\
\text { insumos. }\end{array}\end{array}$ & $\begin{array}{l}\text { Gestión } \\
\text { institucional, } \\
\text { educación y } \\
\text { aprendizaje }\end{array}$ & $\begin{array}{l}\text { Ambiental, social, } \\
\text { económico }\end{array}$ \\
\hline
\end{tabular}




\begin{tabular}{|c|c|c|c|c|}
\hline $\begin{array}{l}\text { Laboratorios } \\
\text { Verdes }\end{array}$ & 3,12 & $\begin{array}{l}\text { Salud y seguridad, energía, } \\
\text { agua, desechos. }\end{array}$ & $\begin{array}{l}\text { Gestión } \\
\text { institucional }\end{array}$ & Ambiental, social \\
\hline $\begin{array}{l}\text { Información } \\
\text { tecnológica }\end{array}$ & 8,9 & $\begin{array}{l}\text { Energía, basura, eficiencia } \\
\text { en las computadoras. }\end{array}$ & $\begin{array}{l}\text { institucional, } \\
\text { educación y } \\
\text { aprendizaje }\end{array}$ & Ambiental \\
\hline Transporte & 11 & $\begin{array}{l}\text { Infraestructura, bicicleta, } \\
\text { auto compartido, pasos } \\
\text { peatonales. }\end{array}$ & $\begin{array}{c}\text { Gestión } \\
\text { institucional }\end{array}$ & Ambiental, social \\
\hline $\begin{array}{l}\text { Aprendizaje, } \\
\text { enseñanza e } \\
\text { investiqación }\end{array}$ & 4 & $\begin{array}{l}\text { Auditorías, } \\
\text { administración. }\end{array}$ & $\begin{array}{c}\text { Gestión } \\
\text { institucional }\end{array}$ & Ambiental \\
\hline
\end{tabular}

Fuente: Elaboración propia con base en UNEP (2014)

Toolkit, representa una vía para la auditoría de IES al margen de los campus verdes, pues principalmente menciona variables a cubrir para que las IES sean sustentables en cuanto a sus instalaciones; sin embargo, en cuanto a las dimensiones de la sustentabilidad coincide en el aspecto ambiental, social, y económico. Al final de documento guía se mencionan casos de éxito alrededor de mundo y las estrategias que han implementado.

\subsection{Organización de las Naciones Unidas (ONU)}

La ONU, en 2015 redacta la Agenda 2030 para el Desarrollo Sostenible que a grandes rasgos es "un plan de acción en favor de las personas, el planeta y la prosperidad" (ONU, 2015) en el que se enaltecen los 17 ODS como estrategias para lograr la sustentabilidad mundial; en el que se destaca a la educación no solo como un objetivo sino como un indicador para lograr diversos ODS. En este sentido, se considera que las funciones sustantivas tienen cabida dentro de los ODS, principalmente en el rubro de la gestión institucional, posteriormente de la educación e investigación, y por último la de liderazgo social (Ver tabla 4)

Tabla 4

Análisis de ODS (2015) considerando ideas principales, y relación con las funciones sustantivas de las universidades y dimensión de la sustentabilidad.

\begin{tabular}{|c|c|c|c|}
\hline ODS & Ideas principales & Función sustantiva & $\begin{array}{l}\text { Dimensión de la } \\
\text { sustentabilidad }\end{array}$ \\
\hline $\begin{array}{l}\text { Fin de la } \\
\text { pobreza }\end{array}$ & 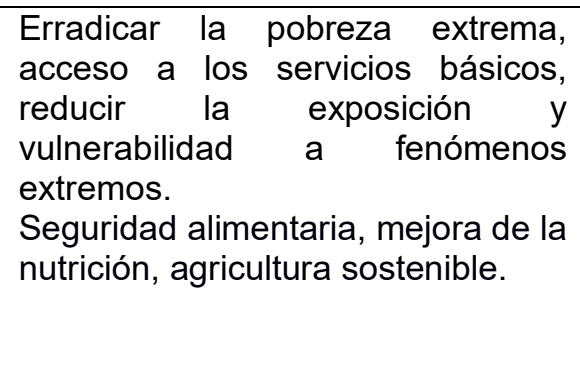 & $\begin{array}{c}\text { Gestión institucional, } \\
\text { educación y } \\
\text { aprendizaje, } \\
\text { investigación, liderazgo } \\
\text { social. } \\
\text { Gestión institucional, } \\
\text { educación y } \\
\text { aprendizaje, } \\
\text { investigación. }\end{array}$ & $\begin{array}{c}\text { Social, } \\
\text { económico, } \\
\text { ambiental }\end{array}$ \\
\hline
\end{tabular}




\begin{tabular}{|c|c|}
\hline $\begin{array}{l}\text { Salud y } \\
\text { bienestar }\end{array}$ & $\begin{array}{l}\text { Mortalidad materna, de recién } \\
\text { nacidos y niños menores de } 5 \text { años, } \\
\text { poner fin a epidemias, prevención y } \\
\text { tratamiento del abuso de sustancias } \\
\text { adictivas, servicios de salud sexual }\end{array}$ \\
\hline & $\begin{array}{l}\text { y reproductiva, vacunas } y \\
\text { medicamentos. }\end{array}$ \\
\hline $\begin{array}{l}\text { ducación de } \\
\text { calidad }\end{array}$ & $\begin{array}{l}\text { Educación inclusiva y equitativa, } \\
\text { educación calidad, } \\
\text { alfabetización, de } \\
\begin{array}{l}\text { adecuadas, becas, docentes } \\
\text { instalaciones } \\
\text { calificados. }\end{array}\end{array}$ \\
\hline $\begin{array}{l}\text { Igual } \\
\text { gé }\end{array}$ & $\begin{array}{l}\text { Empoderar a mujeres y niñas, } \\
\text { eliminar matrimonio infantil, } \\
\text { mutilación genital, igualdad de } \\
\text { derechos económicos, }\end{array}$ \\
\hline
\end{tabular}

Agua limpia y saneamiento

Energía

asequible y no contaminante

Industria, innovación e infraestructura

Reducción de las desigualdades

Ciudades y comunidades sostenibles

Producción y
consumo
responsable

Disponibilidad y calidad de agua.

Acceso a servicios energéticos asequibles, ampliar la infraestructura eléctrica.

Diversificación de empleos, modernización e innovación tecnológica, fomentar la formalización y crecimiento de microempresas, pequeñas $y$ medianas, consumo eficiente de los recursos, igualdad de oportunidades, acceso a servicios bancarios y de seguro.

Infraestructura adecuada para el desarrollo económico, infraestructura sostenible, uso de tecnología.

Promover la inclusión social, oportunidades; políticas migratorias adecuadas.

Acceso a viviendas, servicios básicos adecuados, transporte seguro y asequible, proteger el patrimonio natural y cultural mundial, disminución de víctimas por desastres naturales, disposición adecuada de desechos sólidos urbanos, áreas verdes y espacios públicos seguros, inclusivos $y$ accesibles; infraestructura sustentable.

Uso eficiente de los recursos naturales. Reducción de desperdicio de alimentos; económica y política. Igualdad de

Gestión institucional, educación y aprendizaje, Social investigación.

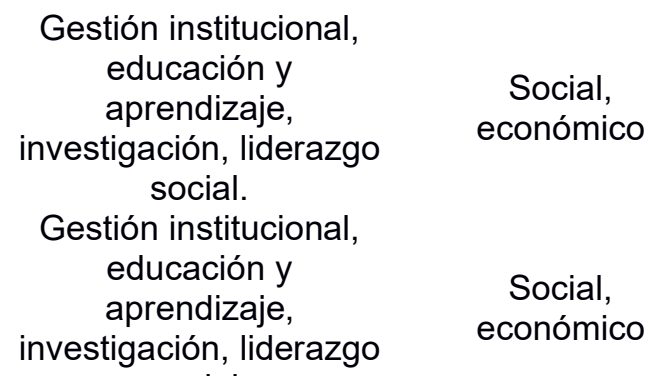

Social, económico

Social, económico

Gestión institucional. Social, ambiental

Gestión institucional. Social, ambiental

\section{Gestión institucional, educación y aprendizaje, \\ Social, económico, investigación, liderazgo ambiental} social.

\section{Gestión institucional, educación y aprendizaje, \\ Social, económico, investigación, liderazgo ambiental} social.

Gestión institucional, liderazgo social.

Social, económico

\section{Gestión institucional, educación y aprendizaje, \\ Social, económico, investigación, liderazgo ambiental} social.
Gestión institucional, educación y aprendizaje,

Social, económico, ambiental 


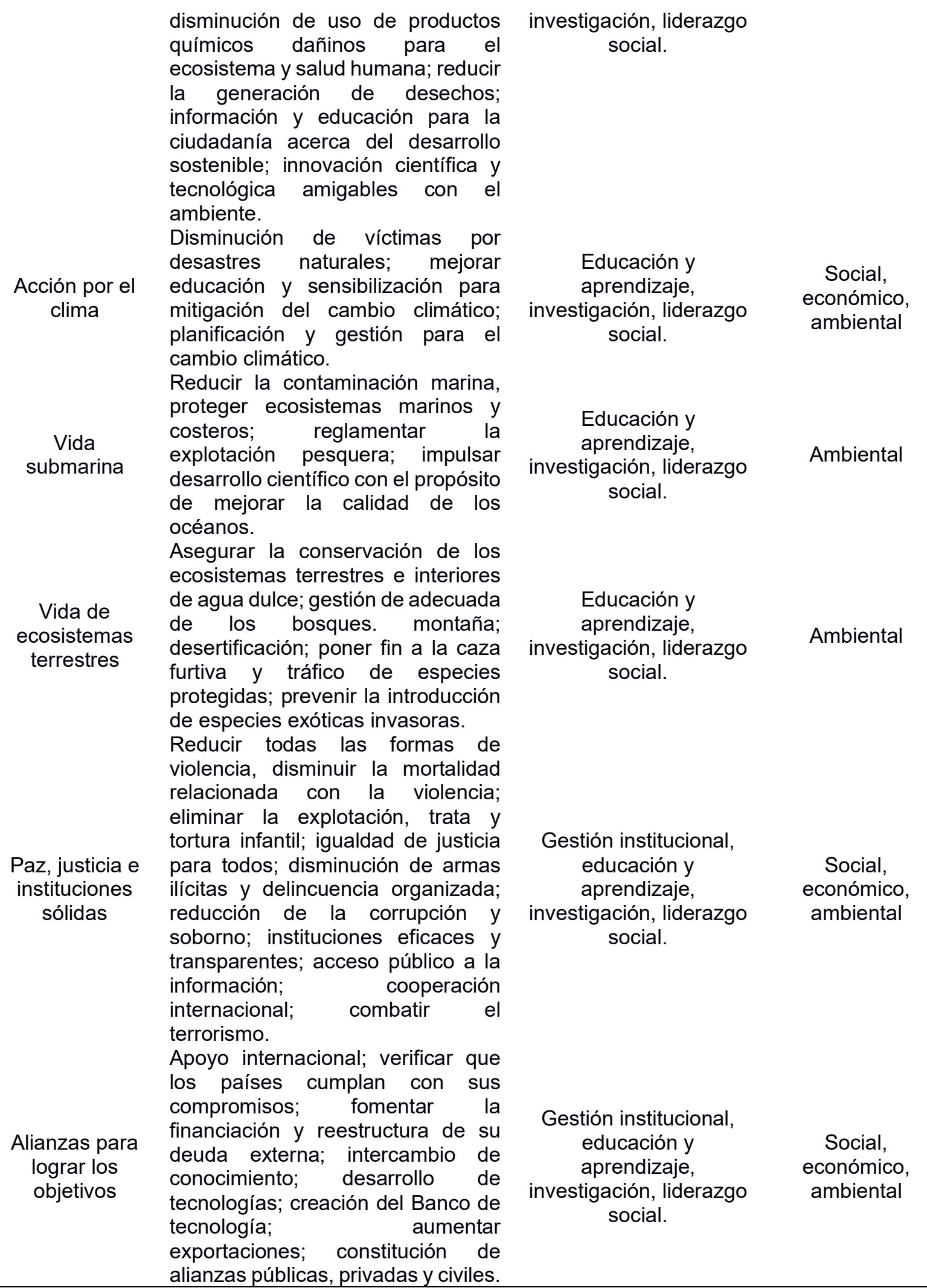

Fuente: Elaboración propia con base en la ONU (2015) 
En la tabla anterior se puede vislumbrar que los ODS señalan vías específicas para lograr la sustentabilidad, ya que se contemplan las tres dimensiones de la sustentabilidad (económico, social, ambiental); sin embargo, tal y como deja entre ver la ONU, los ODS pueden ser difícilmente cumplidos en cuanto a la temporalidad que son planteados, además las estrategias o indicadores si bien son factibles, estos necesitan el apoyo de diversas instancias que vigilen y verifiquen su cumplimiento; una plena disposición de la sociedad civil y de los gobiernos para ejecutar de manera obligatoria los ODS.

\subsection{Conferencia de Rectores de las Universidades Españolas (CRUE)}

CRUE surge en 1994 para coordinar, comunicar, guiar y promover actividades entre las IES, sociedad, gobierno y empresas (CRUE, 2018). En 2017, presentan una herramienta para determinar la sustentabilidad ambiental de las IES españolas, basados en indicadores con relación a la organización, docencia, investigación y gestión (Ver tabla 5).

\section{Tabla 5}

Análisis del vínculo entre CRUE (2018) y ODS (2015), considerando indicadores de CRUE, ODS, criterios, función sustantiva y dimensión de la sustentabilidad.

\begin{tabular}{|c|c|c|c|c|c|}
\hline & CRUE & ODS & Criterios & $\begin{array}{l}\text { Función } \\
\text { sustantiva }\end{array}$ & $\begin{array}{l}\text { Dimensión de la } \\
\text { sustentabilidad }\end{array}$ \\
\hline 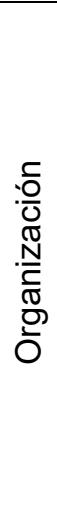 & $\begin{array}{c}\text { Implicación y } \\
\text { sensibilización } \\
\text { de la } \\
\text { comunidad } \\
\text { universitaria }\end{array}$ & 16 & $\begin{array}{l}\text { Recursos financieros, } \\
\text { departamentos encargados del } \\
\text { rubro de sostenibilidad, planes, } \\
\text { trabajo colegiado, } \\
\text { responsabilidad social, redes } \\
\text { sociales, evaluación, auditoría, } \\
\text { certificaciones. } \\
\text { Docencia, } \\
\text { extracurriculares, actividades } \\
\text { departamentos encargados del } \\
\text { rubro de sostenibilidad, } \\
\text { seguimiento puntual de } \\
\text { acciones, becas. }\end{array}$ & $\begin{array}{c}\text { Gestión } \\
\text { institucional, } \\
\text { educación y } \\
\text { aprendizaje }\end{array}$ & Social, ambiental \\
\hline 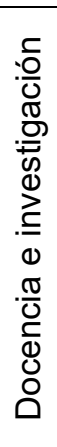 & $\begin{array}{c}\text { Investigación y } \\
\text { transferencia } \\
\text { de } \\
\text { conocimiento }\end{array}$ & 4,9 & $\begin{array}{l}\text { Actualización de planes de } \\
\text { estudio y de docentes, tesis, } \\
\text { incentivos para practicas } \\
\text { sostenibles dentro de la } \\
\text { curricula, innovación educativa. } \\
\text { Difusión del conocimiento, } \\
\text { trabajo colegiado, líneas de } \\
\text { investigación relacionadas con } \\
\text { la sostenibilidad, financiamiento, } \\
\text { becas, tesis, colaboración con } \\
\text { diversos sectores. }\end{array}$ & $\begin{array}{l}\text { Investigación, } \\
\text { liderazgo } \\
\text { social }\end{array}$ & Social, ambiental \\
\hline
\end{tabular}




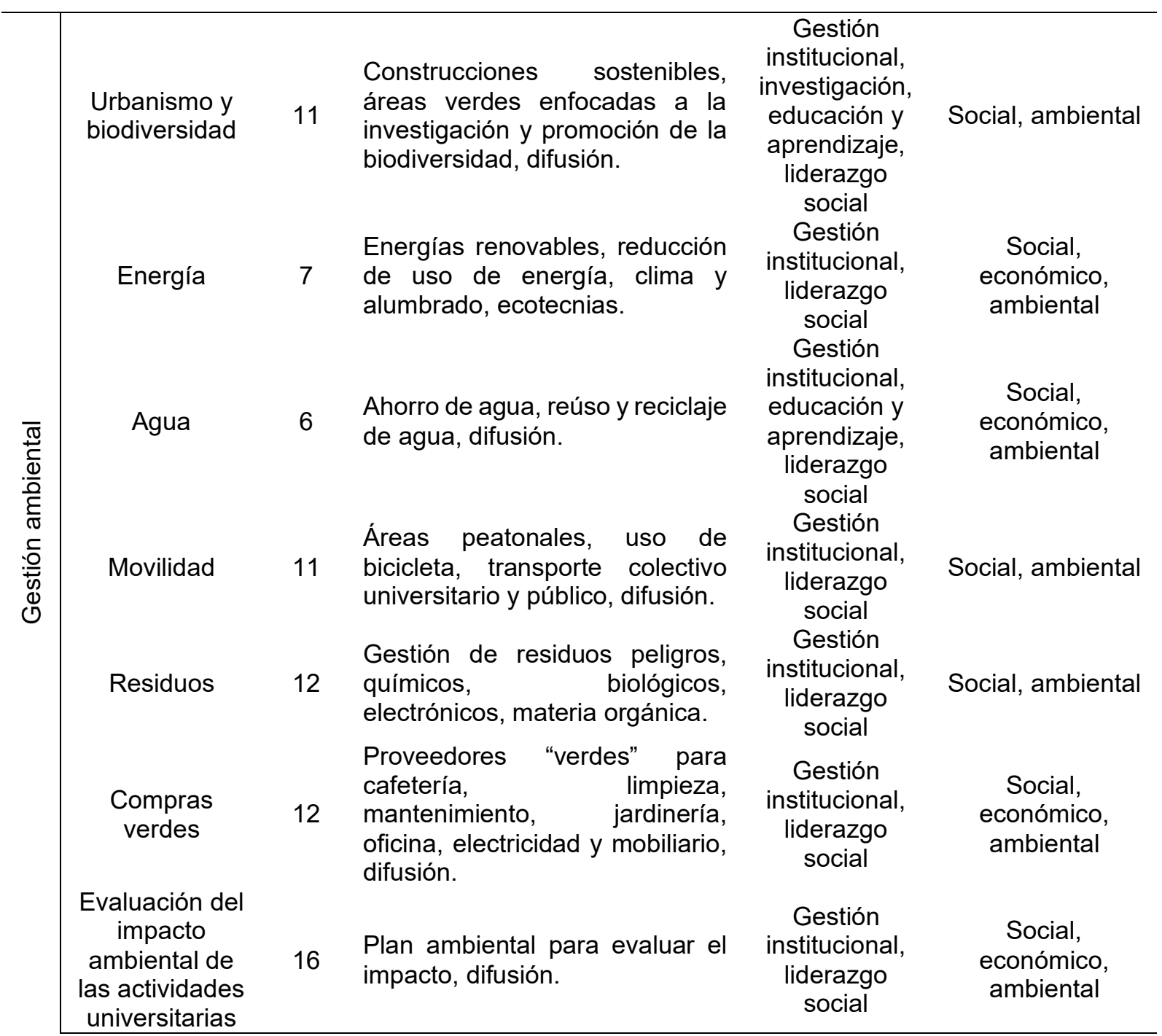

Fuente: Elaboración propia con base en CRUE (2018)

Como se puede vislumbrar, esta propuesta relaciona sus indicadores con dos o tres de las dimensiones de la sustentabilidad (social, ambiental, económico), además utiliza la difusión como base para difundir su quehacer con la sustentabilidad; por lo tanto, la función principal que destaca este programa es la función de liderazgo social; en segundo lugar, la de educación, en tercero la gestión institucional y por último la de investigación.

El documento diseñado por CRUE es de suma importancia ya que hasta el momento es la única propuesta que se ha encontrado que la función sustantiva de liderazgo social es la principal. Sin embargo, el proceso de autoevaluación que desarrolló la organización puede ser sesgada, pues los resultados pueden manejarse a conveniencia al no tener un ente ajeno a la IES para poder evaluarlo imparcialmente. 


\subsection{Asociación Nacional de Universidades e Instituciones de Educación Superior (ANUIES)}

ANUIES presenta en el año 2000 el Plan de Acción para el Desarrollo Sustentable en las Instituciones de Educación Superior, en donde propone estrategias para la oferta educativa, nivel institucional, investigación científica y tecnológica, y difusión del conocimiento científico y tecnológico y de extensión de los servicios, en materia de sustentabilidad dentro de las IES (Ver tabla 6).

Tabla 6

Análisis del vínculo entre ANUIES (2000) y ODS (2015) considerando estrategias de ANUIES, ODS, criterios, función sustantiva y dimensión de la sustentabilidad.

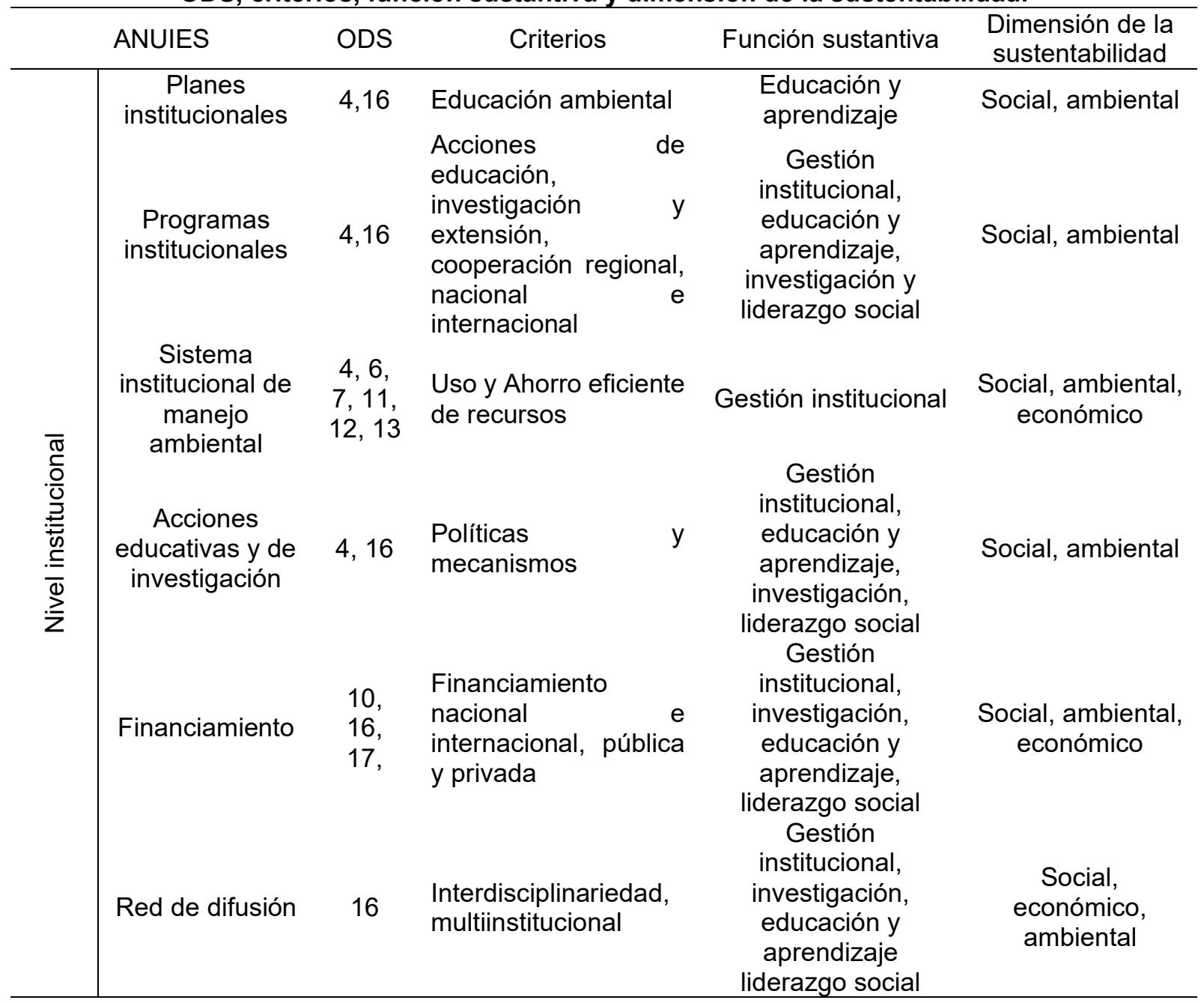




\begin{tabular}{|c|c|c|c|c|c|}
\hline \multirow{4}{*}{ 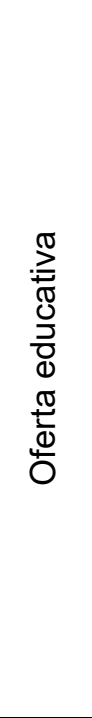 } & $\begin{array}{l}\text { Programas } \\
\text { académicos }\end{array}$ & 4 & $\begin{array}{l}\text { Enfoques } \\
\text { transversales, cultura } \\
\text { ambiental, ampliación } \\
\text { de la oferta educativa } \\
\text { en materia ambiental, } \\
\text { flexibilidad, } \\
\text { innovación, } \\
\text { pertinencia, redes de } \\
\text { trabajo }\end{array}$ & $\begin{array}{c}\text { Educación y } \\
\text { aprendizaje, } \\
\text { investigación, } \\
\text { liderazgo social }\end{array}$ & Social, ambienta \\
\hline & Egresados & $\begin{array}{c}4,8 \\
11,16\end{array}$ & $\begin{array}{l}\text { Compromiso con el } \\
\text { medio ambiente }\end{array}$ & $\begin{array}{c}\text { Educación y } \\
\text { aprendizaje, } \\
\text { liderazgo social } \\
\text { Gestión }\end{array}$ & Social, ambiental \\
\hline & Tecnología & $4,7,9$ & Educación a distancia & $\begin{array}{l}\text { institucional, } \\
\text { educación y } \\
\text { aprendizaje }\end{array}$ & Social, ambiental \\
\hline & $\begin{array}{c}\text { Actualización } \\
\text { docente }\end{array}$ & $\begin{array}{c}4,8 \\
16\end{array}$ & $\begin{array}{l}\text { Programas de } \\
\text { actualización docente }\end{array}$ & $\begin{array}{l}\text { Educación y } \\
\text { aprendizaje }\end{array}$ & Social, ambiental \\
\hline 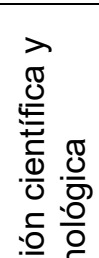 & $\begin{array}{l}\text { Cuerpos } \\
\text { académicos }\end{array}$ & 8 & $\begin{array}{l}\text { Interdisciplinariedad, } \\
\text { líneas de } \\
\text { investigación con } \\
\text { modelo sustentable, } \\
\text { actualización, } \\
\text { financiamiento }\end{array}$ & $\begin{array}{l}\text { Investigación, } \\
\text { liderazgo social }\end{array}$ & Social, ambiental \\
\hline$\underbrace{\bar{D}}_{\mathbb{D}}$ & Tecnología & $4,7,9$ & $\begin{array}{l}\text { Evaluación del } \\
\text { impacto ambiental }\end{array}$ & $\begin{array}{c}\text { Gestión } \\
\text { institucional, } \\
\text { investigación }\end{array}$ & Social, ambiental \\
\hline & Difusión & 13,16 & $\begin{array}{l}\text { Concursos, eventos } \\
\text { académicos }\end{array}$ & $\begin{array}{l}\text { Investigación, } \\
\text { liderazgo social }\end{array}$ & Social, ambiental \\
\hline 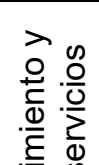 & $\begin{array}{c}\text { Oferta } \\
\text { académica }\end{array}$ & 4,16 & $\begin{array}{l}\text { Formación continua, } \\
\text { ampliar oferta }\end{array}$ & $\begin{array}{c}\text { Gestión } \\
\text { institucional, } \\
\text { educación y } \\
\text { aprendizaje }\end{array}$ & Social, ambiental \\
\hline 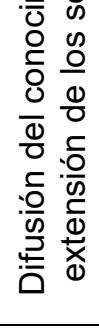 & Difusión & 13,16 & $\begin{array}{l}\text { Servicio social, } \\
\text { prácticas } \\
\text { profesionales, } \\
\text { brigadas o campañas } \\
\text { ambientales, eventos } \\
\text { y publicaciones } \\
\text { académicas, } \\
\text { financiamiento }\end{array}$ & $\begin{array}{l}\text { Educación y } \\
\text { aprendizaje, } \\
\text { investigación, } \\
\text { liderazgo social }\end{array}$ & Social, ambiental \\
\hline
\end{tabular}

Fuente: Elaboración propia con base en ANUIES (2000)

En esta propuesta principalmente tiene cabida la dimensión social y ambiental, pues el aspecto ambiental tiene relación directa en el criterio que propone ANUIES, además, la función sustantiva que sobresale en este documento es el de Educación y aprendizaje, seguido de gestión institucional, investigación y por último el liderazgo social. 


\subsection{Consorcio Mexicano de Programas Ambientales Universitarios para el Desarrollo Sustentable (COMPLEXUS)}

COMPLEXUS fue constituido en el año 2000 y desarrolla sus estrategias para el nivel de estudio superior (IES y posgrado), en donde el documento posee una justificación, definición conceptual, definición operativa, unidades de medida, situación deseable, cálculo, datos y gráficos, fuentes de información, frecuencia de medición, alcances y limitaciones; datos que pueden llevar a COMPLEXUS a ser un documento base para medir la sustentabilidad dentro de las IES, pues los demás documentos no son formulados de esta manera.

COMPLEXUS clasifica sus indicadores con base en las funciones sustantivas de Identidad institucional, educación, investigación, extensión y difusión, y vinculación (COMPLEXUS, 2013); además se puede inferir que el ODS presente en este documento es el 13, que corresponde a acciones por el clima, ya que cada criterio resalta las palabras de medio ambiente y sustentabilidad (Ver tabla 7).

Tabla 7

Análisis del vínculo entre COMPLEXUS (2013) y ODS (2015) considerando funciones sustantivas de COMPLEXUS, ODS, criterios, función sustantiva propuesta y dimensión de la sustentabilidad.

\begin{tabular}{|c|c|c|c|c|c|}
\hline & COMPLEXUS & ODS & Criterios & Función sustantiva & $\begin{array}{c}\text { Dimensión de la } \\
\text { sustentabilidad }\end{array}$ \\
\hline & $\begin{array}{c}\text { Política } \\
\text { institucional }\end{array}$ & $\begin{array}{l}16 \\
17\end{array}$ & $\begin{array}{lrr}\text { Incorporar a } & \text { la } \\
\text { sustentabilidad en la } \\
\text { política institucional, } \\
\text { académico } \\
\text { administrativo. }\end{array}$ & $\begin{array}{c}\text { Gestión } \\
\text { institucional, } \\
\text { educación y } \\
\text { aprendizaje, } \\
\text { liderazgo social }\end{array}$ & $\begin{array}{l}\text { Social, } \\
\text { económico, } \\
\text { ambiental }\end{array}$ \\
\hline & $\begin{array}{l}\text { Asignación } \\
\text { presupuestal }\end{array}$ & $\begin{array}{l}12 \\
16\end{array}$ & Desarrollo de proyectos & $\begin{array}{l}\text { Gestión } \\
\text { institucional }\end{array}$ & $\begin{array}{l}\text { Social, } \\
\text { económico, } \\
\text { ambiental }\end{array}$ \\
\hline 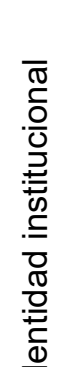 & $\begin{array}{l}\text { Sistema de } \\
\text { Gestión } \\
\text { Ambiental }\end{array}$ & $\begin{array}{c}6 \\
, 7,11 \\
, 12 \\
13 \\
14 \\
15\end{array}$ & $\begin{array}{l}\text { Agua, } \\
\text { infraestructura, conergía, } \\
\text { responsable, compras } \\
\text { verdes, disposición de } \\
\text { residuos sólidos urbanos, } \\
\text { de manejo especial y } \\
\text { peligroso, transporte, } \\
\text { prevención de riesgos, } \\
\text { cultura ambiental. }\end{array}$ & $\begin{array}{l}\text { Gestión } \\
\text { institucional }\end{array}$ & $\begin{array}{l}\text { Social, } \\
\text { económico, } \\
\text { ambiental }\end{array}$ \\
\hline$\tau$ & $\begin{array}{l}\text { Perspectiva de } \\
\text { género }\end{array}$ & 5 & $\begin{array}{l}\text { Sociedades más justas y } \\
\text { equitativas. }\end{array}$ & $\begin{array}{c}\text { Gestión } \\
\text { institucional, } \\
\text { educación y } \\
\text { aprendizaje, } \\
\text { investigación, } \\
\text { liderazgo social }\end{array}$ & $\begin{array}{l}\text { Social, } \\
\text { económico }\end{array}$ \\
\hline & $\begin{array}{l}\text { Protección civil, } \\
\text { riesgos a la } \\
\text { salud, ambiente } \\
\text { y patrimonio }\end{array}$ & $\begin{array}{l}3 \\
11 \\
13\end{array}$ & $\begin{array}{l}\text { Brigadas y programas de } \\
\text { protección civil para medio } \\
\text { ambiente y sociedad. }\end{array}$ & Liderazgo social & Social, ambiental \\
\hline
\end{tabular}




\begin{tabular}{|c|c|c|c|c|c|}
\hline \multirow{6}{*}{ 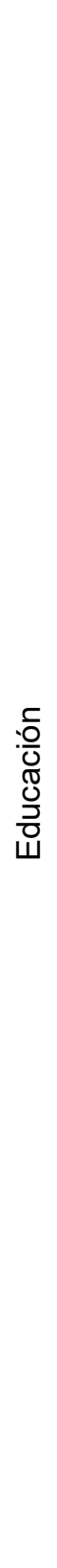 } & $\begin{array}{l}\text { Planes de } \\
\text { estudio } \\
\text { transversales }\end{array}$ & 4,13 & $\begin{array}{l}\text { Planes de estudio con } \\
\text { perspectiva ambiental y de } \\
\text { sustentabilidad a nivel } \\
\text { licenciatura y posgrado, } \\
\text { competencias } \\
\text { permitan la formación } \\
\text { ambiental, } \\
\text { obligatorias, selectivas y } \\
\text { optativas con perspectiva } \\
\text { ambiental, estrategias } \\
\text { didácticas enfocadas a la } \\
\text { sustentabilidad. }\end{array}$ & $\begin{array}{l}\text { Educación y } \\
\text { aprendizaje }\end{array}$ & Social, ambiental \\
\hline & $\begin{array}{l}\text { Formación y } \\
\text { actualización } \\
\text { docente }\end{array}$ & 4,13 & $\begin{array}{l}\text { Actualización docente para } \\
\text { estrategias educativas } \\
\text { relacionadas con temas } \\
\text { ambientales. }\end{array}$ & $\begin{array}{l}\text { Educación y } \\
\text { aprendizaje }\end{array}$ & Social, ambiental \\
\hline & $\begin{array}{l}\text { Educación } \\
\text { continua }\end{array}$ & 4,13 & 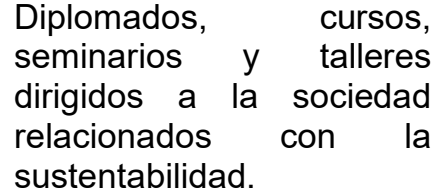 & $\begin{array}{l}\text { Educación y } \\
\text { aprendizaje, } \\
\text { investigación }\end{array}$ & Social, ambiental \\
\hline & $\begin{array}{l}\text { Programas } \\
\text { educativos en } \\
\text { modalidades } \\
\text { alternativas }\end{array}$ & 4,13 & $\begin{array}{l}\text { Uso de tecnologías de } \\
\text { comunicación } \\
\text { información; modalidades } \\
\text { alternativas de educación: } \\
\text { abierta, a distancia y } \\
\text { virtual; capacitación. }\end{array}$ & $\begin{array}{l}\text { Educación y } \\
\text { aprendizaje }\end{array}$ & Social, ambiental \\
\hline & $\begin{array}{c}\text { Planes de } \\
\text { estudio } \\
\text { especializados } \\
\text { en temáticas } \\
\text { ambientales y } \\
\text { de } \\
\text { sustentabilidad }\end{array}$ & 4,13 & $\begin{array}{l}\text { Incorporar dimensión } \\
\text { sociocultural, ambiental, } \\
\text { económica; planes de } \\
\text { estudio multidisciplinarios; } \\
\text { redes de trabajo; impulso } \\
\text { de la tecnología. }\end{array}$ & $\begin{array}{l}\text { Educación y } \\
\text { aprendizaje, } \\
\text { investigación }\end{array}$ & Social, ambiental \\
\hline & $\begin{array}{l}\text { Participación de } \\
\text { estudiantes y } \\
\text { miembros del } \\
\text { claustro en } \\
\text { proyectos para } \\
\text { la } \\
\text { sustentabilidad }\end{array}$ & 4,13 & $\begin{array}{l}\text { Incorporar contenido de } \\
\text { educación ambiental en } \\
\text { sus } \\
\text { académicas; educación no } \\
\text { formal. }\end{array}$ & $\begin{array}{l}\text { Educación y } \\
\text { aprendizaje }\end{array}$ & Social, ambiental \\
\hline 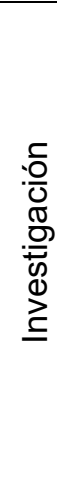 & $\begin{array}{c}\text { Grupos } \\
\text { multidisciplinari } \\
\text { os }\end{array}$ & $\begin{array}{c}4 \\
13,1 \\
7\end{array}$ & $\begin{array}{l}\text { Reforzar enfoques } \\
\text { multidisciplinarios } \\
\text { existentes, promover } \\
\text { estudios interdisciplinarios } \\
\text { para temas prioritarios } \\
\text { como el agua, salud, } \\
\text { energía, agricultura, } \\
\text { biodiversidad, erradicación } \\
\text { de la pobreza, } \\
\text { conservación de recursos } \\
\text { naturales, cambio } \\
\text { climático, entre otras. }\end{array}$ & Investigación & Social, ambiental \\
\hline
\end{tabular}




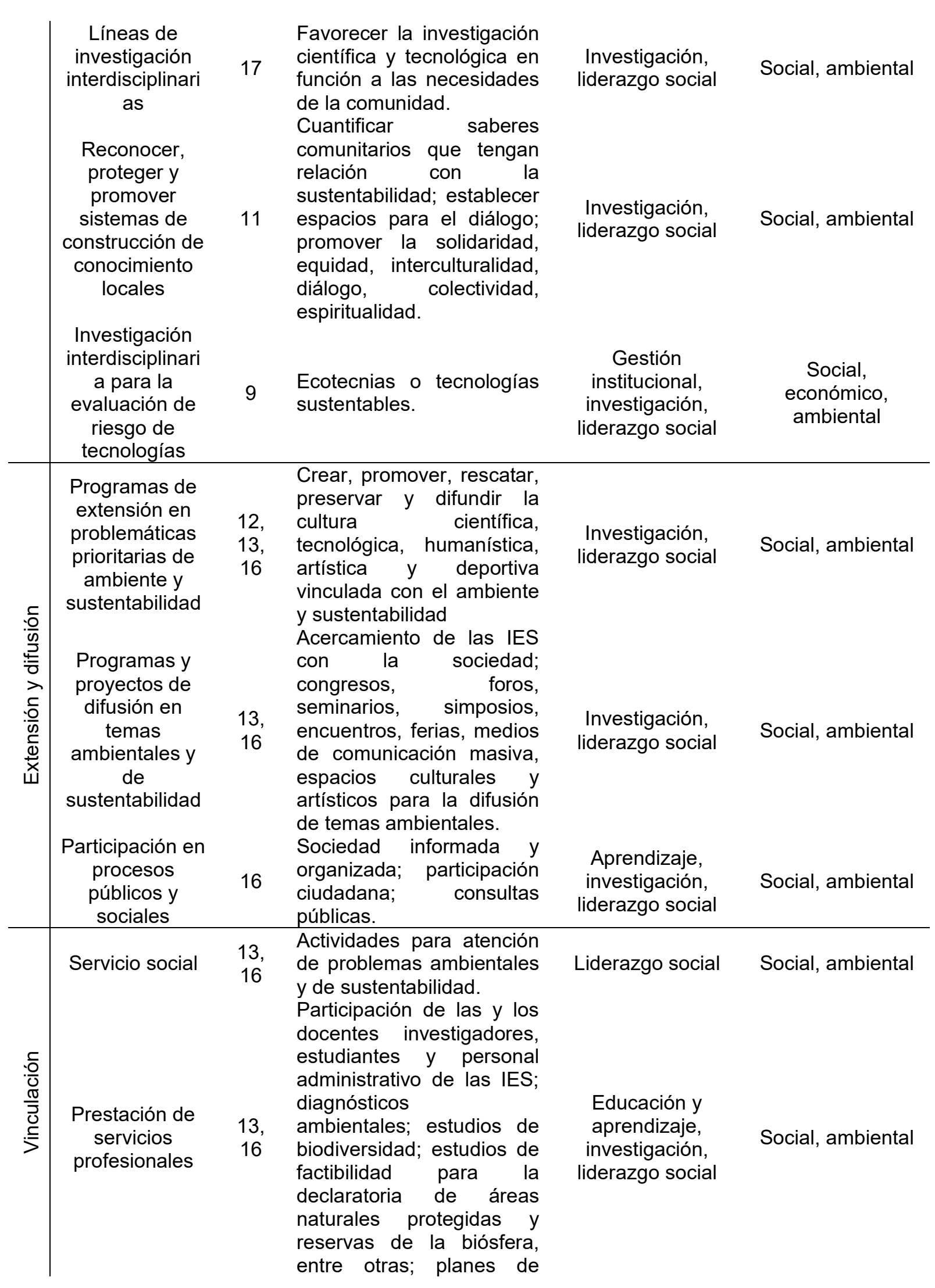




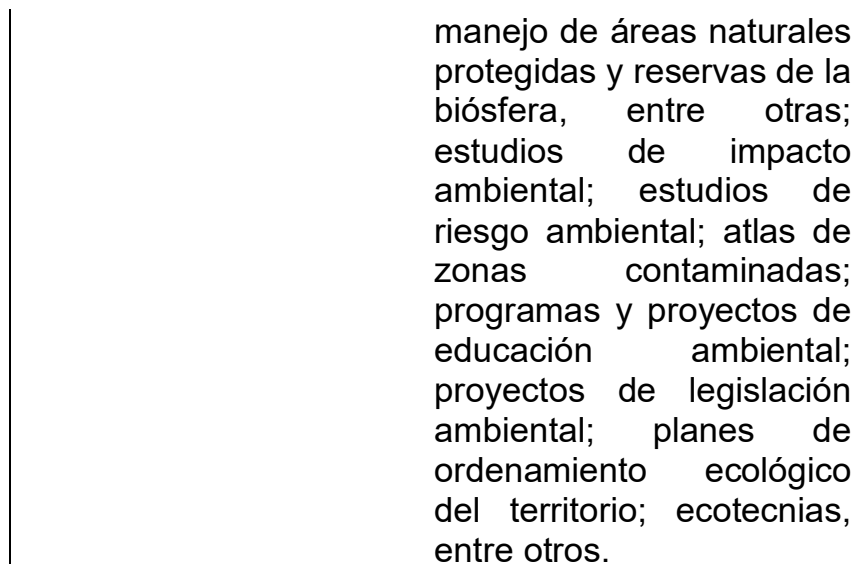

Participación en redes universitarias con organismos gubernamental es y de la sociedad civil,
Cooperación

interinstitucional, beneficio para egresados; participación de la IES en redes nacionales e internacionales.
Educación y aprendizaje, investigación,

Social, ambiental

COMPLEXUS es un documento que contiene indicadores interesantes que pueden ser retomados para lograr los ODS; pues integra a la sustentabilidad como fundamento para cada uno de los indicadores, principalmente la dimensión social; además de ser un documento que está centrado en nivel licenciatura y posgrado, y tiene una clasificación en relación con las funciones sustantivas de las IES.

\subsection{Secretaría de Educación Pública (SEP)}

La SEP en 2013 desarrolla una base de datos para las IE de todos los niveles, la cual se conoce como Formato 911, misma que mide aspectos cuantitativos de las instituciones (SEP, 2020).

El Formato 911 para nivel posgrado y superior evalúa nueve aspectos, que de acuerdo con las funciones sustantivas de las IES tienen cabida principalmente para la gestión institucional, pues las demás funciones no están presentes en este apartado. Además de acuerdo con el cumplimiento de los ODS, ayuda principalmente a los objetivos 4 y 12 (Ver tabla 8). 
Tabla 8

Análisis del vínculo entre SEP (2020) y ODS (2015) considerando aspectos que mide la SEP, ODS, criterios, función sustantiva y dimensión de la sustentabilidad.

\begin{tabular}{|c|c|c|c|c|}
\hline SEP & ODS & Criterios & Función sustantiva & $\begin{array}{c}\text { Dimensión de } \\
\text { la } \\
\text { sustentabilidad }\end{array}$ \\
\hline Modalidad & 4,12 & $\begin{array}{l}\text { Escolarizada, mixta, abierta, } \\
\text { virtual o a distancia }\end{array}$ & $\begin{array}{l}\text { Educación y } \\
\text { aprendizaje }\end{array}$ & Social \\
\hline $\begin{array}{l}\text { Registro de la } \\
\text { Validez Oficial }\end{array}$ & 4,12 & $\begin{array}{c}\text { Dependencia a la que } \\
\text { pertenece }\end{array}$ & Gestión institucional & Social \\
\hline $\begin{array}{l}\text { Característica } \\
\text { del programa }\end{array}$ & 4 & $\begin{array}{c}\text { Grado académico en curso, } \\
\text { fecha de creación o } \\
\text { actualización del plan de } \\
\text { estudios, duración del } \\
\text { programa y tipo de estructura } \\
\text { del plan (años, semestres, } \\
\text { cuatrimestre, entre otros), } \\
\text { número de créditos, período } \\
\text { de admisión }\end{array}$ & $\begin{array}{c}\text { Gestión institucional, } \\
\text { educación y } \\
\text { aprendizaje }\end{array}$ & Social \\
\hline $\begin{array}{l}\text { Períodos de } \\
\text { inscripción }\end{array}$ & 4 & $\begin{array}{l}\text { Número de período de } \\
\text { inscripción, número de } \\
\text { alumnos de nuevo ingreso por } \\
\text { sexo, egresados y graduados }\end{array}$ & $\begin{array}{c}\text { Gestión institucional, } \\
\text { educación y } \\
\text { aprendizaje, liderazgo } \\
\text { social }\end{array}$ & Social \\
\hline $\begin{array}{l}\text { Egresados y } \\
\text { graduados }\end{array}$ & 4 & $\begin{array}{l}\text { Por sexo, discapacidad y } \\
\text { hablantes de lengua indígena }\end{array}$ & $\begin{array}{c}\text { Gestión institucional, } \\
\text { educación y } \\
\text { aprendizaje, liderazgo } \\
\text { social }\end{array}$ & Social \\
\hline $\begin{array}{l}\text { Movilidad de } \\
\text { alumnos }\end{array}$ & 12 & $\begin{array}{l}\text { Por sexo, nacional o } \\
\text { internacional }\end{array}$ & $\begin{array}{l}\text { Gestión institucional, } \\
\text { educación y } \\
\text { aprendizaje, } \\
\text { investigación, liderazgo } \\
\text { social }\end{array}$ & Social \\
\hline $\begin{array}{l}\text { Alumnos de } \\
\text { primer ingreso }\end{array}$ & 4 & $\begin{array}{l}\text { Lugares ofertados, solicitudes } \\
\text { recibidas, estudiantes con } \\
\text { título, sin título profesional del } \\
\text { nivel inmediato anterior, lugar } \\
\text { de procedencia, rango de } \\
\text { edad }\end{array}$ & $\begin{array}{c}\text { Gestión institucional, } \\
\text { educación y } \\
\text { aprendizaje, liderazgo } \\
\text { social }\end{array}$ & Social \\
\hline Matricula total & 4 & $\begin{array}{l}\text { Por sexo, discapacidad, } \\
\text { mexicanos nacidos fuera de } \\
\text { México, hablantes indígenas, } \\
\text { total de alumnos }\end{array}$ & $\begin{array}{l}\text { Gestión institucional, } \\
\text { educación y } \\
\text { aprendizaje, liderazgo } \\
\text { social }\end{array}$ & Social \\
\hline $\begin{array}{l}\text { Gasto por } \\
\text { alumno en } \\
\text { educación }\end{array}$ & 4,12 & $\begin{array}{l}\text { Cuota voluntaria, inscripción, } \\
\text { colegiatura, material educativo }\end{array}$ & $\begin{array}{l}\text { Gestión institucional, } \\
\text { educación y } \\
\text { aprendizaje, } \\
\text { investigación, liderazgo } \\
\text { social }\end{array}$ & $\begin{array}{l}\text { Social, } \\
\text { económico }\end{array}$ \\
\hline
\end{tabular}

Fuente: Elaboración propia con base en la SEP (2020)

El Formato 911, es opcional para las instituciones, y va en función a la información y documentos que brinde la población estudiantil. Por lo tanto, los datos obtenidos pueden presentar sesgo al no corroborar esta información y no tener apertura a más opciones de 
respuestas. Además, la dimensión de la sustentabilidad que está presente en este documento es la social.

Ahora bien, los criterios que se considera que son relevantes que aborda cada documento son los siguientes: Normatividad o política institucional, organización o cooperación colegiada, infraestructura, evaluación institucional de calidad, asignación presupuestal, sistema de gestión ambiental, participación de las mujeres, protección civil, energía, residuos, movilidad, agua, publicidad, compras verdes, proceso de admisión, atención a problemáticas, seguimiento laboral, planes de estudio, formación de competencias, pertinencia, congruencia y eficiencia, actualización del personal docente, uso de tecnología, becas, difusión y divulgación de investigación, redes de trabajo, movilidad nacional e internacional del alumnado y profesorado, responsabilidad socioambiental/sensibilización, seguimiento a egresados, vinculación con diferentes sectores, calidad y pertinencia de la tesis (Ver tabla 9).

Tabla 9

Criterios para abordar la sustentabilidad en las Instituciones de Educación Superior con base en la categoría de análisis de las funciones sustantivas de la actividad universitaria. Periodo 1998-2020

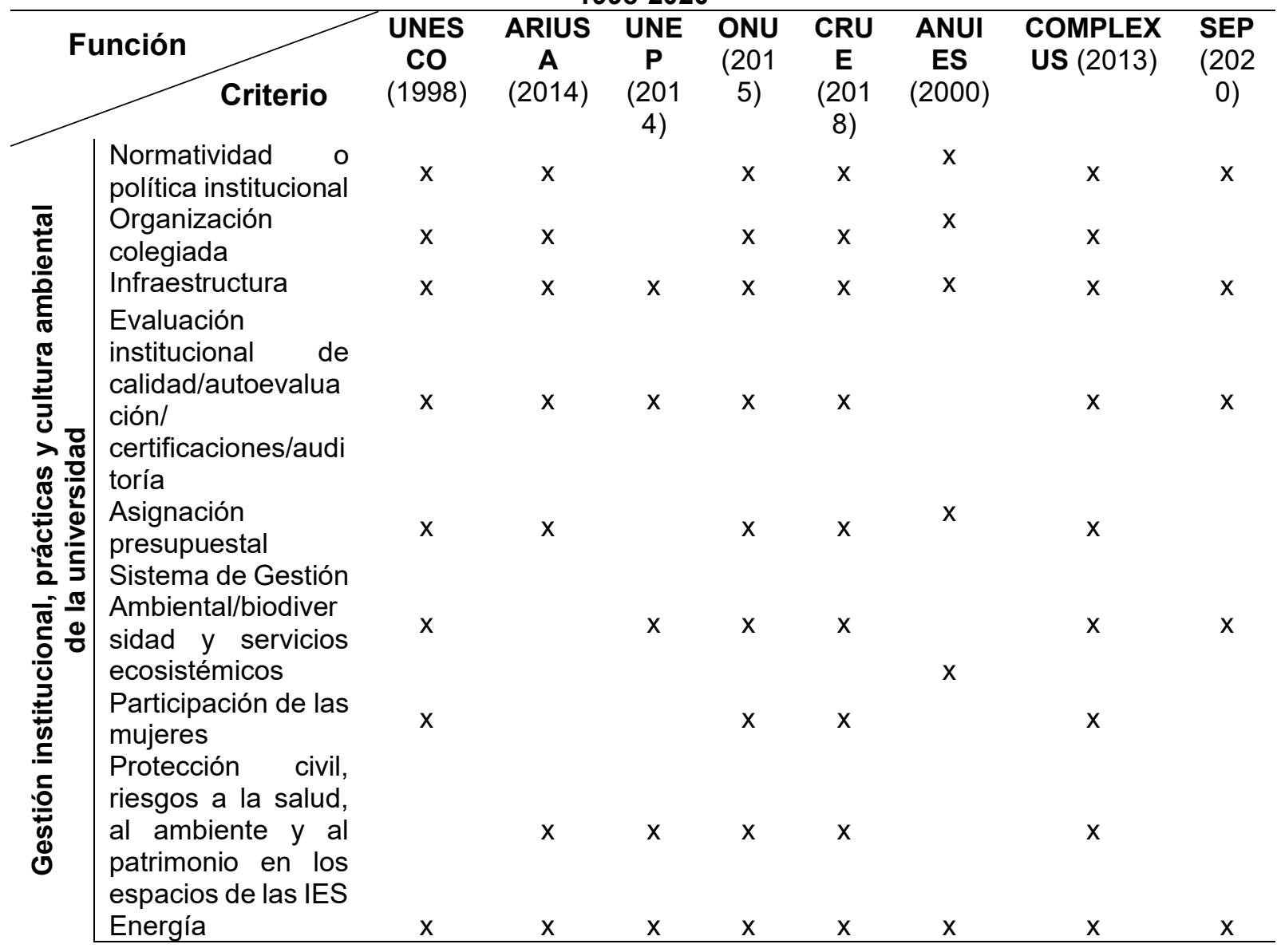




\begin{tabular}{|c|c|c|c|c|c|c|c|c|c|}
\hline & Residuos & $x$ & $x$ & $x$ & $\mathrm{x}$ & $\mathrm{x}$ & $x$ & $x$ & $x$ \\
\hline & $\begin{array}{l}\text { Movilidad } \\
\text { (transporte) }\end{array}$ & & $x$ & $x$ & $x$ & $\mathrm{x}$ & & $x$ & $x$ \\
\hline & Agua & $x$ & $x$ & $x$ & $\mathrm{x}$ & $x$ & $\mathrm{x}$ & $x$ & $x$ \\
\hline & Publicidad & & & $x$ & $x$ & $x$ & $x$ & $x$ & \\
\hline & Compras verdes & & $x$ & $x$ & $x$ & $x$ & $x$ & & $x$ \\
\hline & $\begin{array}{l}\text { Proceso } \\
\text { admisión }\end{array}$ & $x$ & & & $x$ & & & $x$ & \\
\hline & $\begin{array}{l}\text { Atención a } \\
\text { problemáticas }\end{array}$ & $x$ & $\mathrm{x}$ & $\mathrm{x}$ & $\mathrm{x}$ & $\mathrm{x}$ & & $\mathrm{x}$ & \\
\hline & $\begin{array}{l}\text { Seguimiento } \\
\text { laboral }\end{array}$ & $x$ & $\mathrm{x}$ & & $\mathrm{x}$ & $\mathrm{x}$ & $\mathrm{x}$ & $\mathrm{x}$ & $\mathrm{x}$ \\
\hline & Planes de estudio & & & & & & $\mathrm{x}$ & & \\
\hline$\stackrel{0}{\frac{N}{N}}$ & $\begin{array}{l}\text { transversales } \quad y \\
\text { actualizados }\end{array}$ & $x$ & $x$ & & $x$ & $x$ & & $x$ & $x$ \\
\hline$\frac{\overline{\overline{0}}}{\bar{c}}$ & $\begin{array}{l}\text { Formación de } \\
\text { competencias }\end{array}$ & $x$ & & & $x$ & $\mathrm{x}$ & $x$ & $x$ & \\
\hline$\overline{\frac{2}{\sigma}}$ & Pertinencia & $x$ & & & $\mathrm{x}$ & & $\mathrm{x}$ & $x$ & \\
\hline$\stackrel{\lambda}{\underline{c}}$ & $\begin{array}{l}\text { Congruencia } \quad y \\
\text { eficiencia }\end{array}$ & & & & $x$ & & $x$ & $x$ & \\
\hline $\begin{array}{l}\bar{U} \\
\mathbb{8} \\
\end{array}$ & $\begin{array}{l}\text { Actualización de } \\
\text { las y los profesores }\end{array}$ & $\mathrm{x}$ & $x$ & & $x$ & $x$ & $x$ & $x$ & $\mathrm{x}$ \\
\hline 훔 & Uso de tecnología & $x$ & $\mathrm{x}$ & $\mathrm{x}$ & $\mathrm{x}$ & $x$ & $x$ & $x$ & $\mathrm{x}$ \\
\hline & Becas & $x$ & $x$ & & $x$ & & & & $x$ \\
\hline & Investigación & $x$ & $x$ & & $\mathrm{x}$ & $\mathrm{x}$ & $\mathrm{x}$ & $\mathrm{x}$ & $x$ \\
\hline 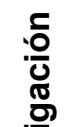 & $\begin{array}{lr}\text { Difusión } & y \\
\text { divulgación } & \text { de } \\
\text { investigación } & \end{array}$ & $x$ & $\mathrm{x}$ & $\mathrm{x}$ & $\mathrm{x}$ & $\mathrm{x}$ & $x$ & $\mathrm{x}$ & $\mathrm{x}$ \\
\hline 要 & Redes de trabajo & $x$ & $x$ & & $x$ & $x$ & $\mathrm{x}$ & $x$ & $x$ \\
\hline$\stackrel{0}{\geqq}$ & $\begin{array}{l}\text { Movilidad nacional } \\
\text { de discentes y } \\
\text { profesorado }\end{array}$ & $x$ & & & $\mathrm{x}$ & & $x$ & $\mathrm{x}$ & \\
\hline$\overline{\frac{\pi}{0}}$ & $\begin{array}{l}\text { Responsabilidad } \\
\text { socioambiental/ } \\
\text { sensibilización }\end{array}$ & $x$ & $x$ & & $x$ & $x$ & $x$ & $x$ & $\mathrm{x}$ \\
\hline $\begin{array}{l}0 \\
0 \\
0\end{array}$ & $\begin{array}{l}\text { Seguimiento a } \\
\text { egresados }\end{array}$ & $x$ & & & $x$ & & $x$ & $\mathrm{x}$ & \\
\hline ำ & $\begin{array}{l}\text { Vinculación con los } \\
\text { diferentes sectores }\end{array}$ & $x$ & $\mathrm{x}$ & & $x$ & $\mathrm{x}$ & $x$ & $x$ & $\mathrm{x}$ \\
\hline$\frac{\overline{0}}{3}$ & $\begin{array}{lll}\text { Calidad } & & y \\
\text { pertinencia de } & \text { la } \\
\text { tesis } & & \end{array}$ & & & & $\mathrm{x}$ & & & $\mathrm{x}$ & $\mathrm{x}$ \\
\hline
\end{tabular}

Fuente: Elaboración propia.

\section{Discusión}

Los documentos anteriores han empleado diversos criterios e indicadores ambientales para la valoración de la sustentabilidad en las IES y Cl. Se observa una tendencia marcada para la gestión institucional por los documentos de Toolkit 2.0, PROYECTO RISU y GESUCRUE, mientras que COMPLEXUS, muestra indicadores más homogéneos en relación con la 
gestión institucional, investigación, docencia y liderazgo. Además, la ONU, a través de la Agenda 2030 no vislumbra las funciones sustantivas de liderazgo social e investigación; mientras que la función sustantiva de la educación debe versar en la formación de seres humanos plenos, libres, y no de brindar únicamente herramientas que pretenden estar acorde un sistema económico como fuerza de trabajo, como la mayoría de los documentos lo deja entrever.

Las únicas propuestas que consideran la mayoría de los indicadores propuestos son la UNESCO (1998) pues comienza a vislumbrar algunos de los ODS (sin aún ser nombrados así en ese año) y su pertinencia en la educación; y COMPLEXUS (2013), que únicamente no contempla el indicador de compras verdes para abastecer la institución.

Los documentos que señalan a la sustentabilidad dentro de sus indicadores de manera específica son Toolkit, PROYECTORISU, GESU-CRUE, UNESCO, ANUIES y COMPLEXUS; por otro lado, el Formato 911 no vislumbra este aspecto, o al menos no está escrito en el documento base.

Se observa también, que los 17 ODS se encuentran presentes en cada uno de los indicadores de las cuatro funciones sustantivas; por lo tanto, se puede plantear que las instituciones superiores pueden impulsar el cumplimiento de los ODS de manera autónoma; sin embargo, si se desea que los 17 objetivos, y especialmente el último sea cubierto en su totalidad, las IES deben trabajar con instancias públicas y privadas para obtener mayor recurso tanto humano como financiero.

Los ODS que tienen mayor relación con las funciones sustantivas son los que corresponden a la educación (ODS 4), trabajo decente y crecimiento económico (ODS 8), las ciudades y comunidades sostenibles (ODS 11), producción y consumo responsables (ODS 12), y alianzas para lograr los objetivos (ODS 17). Bajo este tenor, de acuerdo con la base de datos de Elsevier, con la relación a estos cinco objetivos, hasta el 2020 había 30,990 publicaciones relacionadas con el ODS 4, y se pueden señalar las aportaciones de Borges, Ferreira, Borges de Oliveira, Macini y Caldana (2017) y Annan-Diab y Molinari (2017) quienes enfatizan que la educación puede ayudar a contribuir al cumplimiento de los ODS y de la sustentabilidad, además del desarrollo de la sociedad.

Para el ODS 8 hubo el resultado de 110,464 publicaciones, y se enfatizan los documentos de Martínez-Campillo y Fernández-Santos (2020) que mencionan la capacidad de adaptación de las instituciones educativas ante la crisis económica mundial, y el cómo algunas IES actualmente se han enfocado a fortalecer el ámbito económico de la 
sustentabilidad en las instituciones (Abad-Segura y González-Zamar, 2021). El ODS 11 contaba en 2020 con 172,379 publicaciones relacionadas, en la que destaca la contribución de Kaviti, Currie, Smit, y Kovacic (2020) que mencionan que la creación de ciudades sustentables debe de desarrollarse de la mano de la comunidad.

Mientras que el ODS 12 vinculado al consumo y producción sustentable, tenía 103, 535 publicaciones, y se destacan las investigaciones de Bucio-Gutiérrez, Jiménez-Almaguer y Azuela-Flores (2020) y Pacheco-Blanco y Bastante-Ceca (2016) mencionan que el consumo y producción sustentable están vinculados al comportamiento y consciencia ambiental de las y los individuos, cualidades que se deben reforzar en el plan de estudios de las universidades.

Por otra parte, algunas de las limitaciones del estudio, es que los indicadores propuestos si bien corresponden a las funciones sustantivas de las IES, la correlación que se pretende establecer con los ODS puede ser discutible pues no se han hallado en la práctica propuestas parecidas, pues en su mayoría se han encontrado artículos con relación al vínculo entre los ODS y la sustentabilidad en las IES, lo cual se puede ejemplificar con Ambrosio, Silva-Oliverira y Da Silva (2019) Casarejos, Morten y Nogueira (2017) y Filho et al. (2019), quienes señalan que los ODS, deben estar presentes a través de la enseñanza de buenas prácticas en las IES; es decir, fortalecer los campus verdes. Otra limitación es que es un análisis del contenido,y por lo tanto, se puede realizar un análisis del discurso para establecer relaciones ideológicas,semióticas y semánticas entre las y los actores que se analizan con el contexto de su producción y la asimilación de sus propuestas por la comunidad académica. Una restricción más es que se realiza un aporte teórico que no se puede generalizar dentro del contexto de todas las IES; sin embargo, esta investigación permite abrir un debate y en un futuro se aporten elementos empíricos del estado del arte de la sustentabilidad en las IES.

\section{Conclusiones}

Los ODS corresponden tanto a un marco cualitativo como cuantitativo de las naciones que los desean implementar, por lo que cada gobierno diseña las políticas adecuadas para alcanzarlos de una manera transversal abarcando el mayor número de objetivos con el menor número de recursos. Por lo tanto, se considera que si una herramienta es capaz de satisfacer la mayoría de los ODS puede ayudar a contribuir a la sustentabilidad en el menor tiempo posible, en el que se comprueba su eficiencia para poder destinar recursos financieros, humanos y tecnológicos; es por ello que la Educación Superior adquiere un papel fundamental para el cumplimiento de los ODS, a partir de las funciones sustantivas de gestión institucional, 
educación y aprendizaje, investigación y liderazgo social, pues constituyen una opción para afrontar los retos de una manera colegiada y en su mayoría autónoma, determinada principalmente por tener una constitución multidisciplinaria e interdisciplinaria.

El cumplimiento de los ODS por parte de las IES puede impulsar una sociedad e institución sustentable, al fortalecer su capacidad de interacción con la sociedad, la educación formal e informal, la apertura a nuevas investigaciones y la mejora de los procesos e infraestructura de las instituciones educativas, lo que promueve un desempeño como agentes de cambio que conocen las necesidades de la población. La formulación de criterios de análisis permite comprender los alcances y limitaciones para la sustentabilidad en la Educación Superior, en el que se permite un mayor control, ejecución y adecuación de políticas educativas en favor de la sustentabilidad.

De acuerdo con el análisis que se realizó, los ODS que podrían cumplirse de manera eficaz con el apoyo de las IES son la educación (ODS 4), trabajo digno y crecimiento económico (ODS 8), industria, innovación e infraestructura (ODS 9), ciudades y comunidades sostenibles (ODS 11), producción y consumo responsables (ODS 12), y alianzas para lograr los objetivos (ODS 17). Mientras que la función sustantiva que tiene mayor relevancia para las IES es la investigación, pues es el indicador que aparece con mayor frecuencia dentro de los documentos analizados. Sin embargo, lo hallado en la literatura contrasta con este apartado, ya que la función de gestión institucional, prácticas y cultura ambiental de la universidad, y la función de educación, son los que tienen mayor número de publicaciones. Además, BautistaPuig y Sanz-Casado (2021) mencionan que las IES han dejado relegado la dimensión social, pues sus esfuerzos se encaminan a fortalecer la conservación y uso eficiente de los recursos de las mismas IES; es por ello que se debe impulsar el fortalecimiento de las IES con su compromiso por la sustentabilidad en un marco de acción para construir un campus social, pues por lo que se ha analizado en los documentos, hay una tendencia para dar prioridad a los campus verdes, señalado a través de su gestión institucional.

Por lo anterior, existe una necesidad para realizar estudios posteriores, por ejemplo, el generar una agenda capaz de homogeneizar los criterios de cada propuesta para el cumplimiento con los ODS, además de una retroalimentación a través de escalas de evaluación para medir no solo el aspecto cuantitativo, sino de manera cualitativa generar estrategias tangibles; además el de conocer cuál es la dimensión de la sustentabilidad que más se valora y cuál dimensión tiene mayor presencia en la comunidad epistémica; y por último 
la necesidad de crear campus sociales, para enaltecer la educación como ODS y estrategia que las IES poseen para lograr los otros ODS.

\section{Referencias}

Abad-Segura, Emilio. y González-Zamar, Mariana. (2021). Sustainable economic development in higher education institutions: A global analysis within the SDGs framework. Journal of Cleaner Production, 294. DOI https://doi.org/10.1016/.j.jclepro.2021.126133

Alianza de Redes Iberoamericanas de Universidades por la Sustentabilidad y el Ambiente (ARIUSA). (2014). Definición de indicadores para la evaluación de las políticas de sustentabilidad en Universidades Latinoamericanas. España: Universidad Autónoma de Madrid. Recuperado de https://www.iauhesd.net/sites/default/files/documents/proyecto risu final 2014.pdf

Ambrosio, Aline., Silva-Oliverira, Keilla., y Da Silva, Raquel. (2019). Education for advancing the implementation of the Sustainable Development Goals: A systematic approach. The International Journal of Management Education, 17(3). DOI https://doi.org/10.1016/j.ijme.2019.100322

Annan-Diab, Fátima., and Molinari, Carolina. (2017). Interdisciplinarity: Practical approach to advancing education for sustainability and for the Sustainable Development Goals. The International Journal of Management Education, 15(2), 73-83. DOI: https://doi.org/10.1016/.ijme.2017.03.006

Arechavala, Ricardo. (2011). Las universidades y el desarrollo de la investigación científica y tecnológica en México: Una agenda de investigación. Revista de la Educación Superior, 40(158), 41-57. Recuperado de https://www.redalyc.org/pdf/604/Resumenes/Resumen 60422563003 1.pdf

Arráez, Morella., Calles, Josefina., Moreno de Tovar, Liuval. (2006). La Hermenéutica:una actividad interpretativa. Sapiens. Revista Universitaria de Investigación, 7(2), 171-181. Recuperado de https://www.redalyc.org/articulo.oa?id=41070212

Asociación Nacional de Universidades e Instituciones de Educación Superior (ANUIES). (2000). Plan de Acción para el Desarrollo Sustentable en las Instituciones de Educación Superior. Propuesta de ANUIES y SERMARNAT. Recuperado de http://www2.uadec.mx/pub/pdf/plan acc sintesis.pdf

Avilés, René. (2009). ¿Las funciones sustantivas de la universidad pública son realmente tres? Intertexto con Laura Regil Vargas: Difusión cultural universitaria: entre el ocaso y el porvenir. Reencuentro, (56), 66-69, Recuperado de https://www.redalyc.org/articulo.oa?id=340/34011860012

Bautista-Puig, Núria., y Sanz-Casado, Elías. (2021). Sustainability practices in Spanish higher education institutions: An overview of status and implementation. Journal of Cleaner Production, 295. DOI https://doi.org/10.1016/j.jclepro.2021.126320 
Borges, Julio., Ferreira, Tamiris., Borges de Oliveira, Marcelo., Macini, Nayele., Caldana, Adriana. (2017). Hidden curriculum in student organizations: Learning, practice, socialization and responsible management in a business school. The International Journal of Management Education, 15(2), 153-161. DOI https://doi.org/10.1016/j.ijme.2017.03.003

Bucio-Gutiérrez, Daniel., Jiménez-Almaguer, Karla. y Azuela-Flores, José. (2020). Intención de compra verde. Investigación administrativa, 49(125). Recuperado de http://www.redalyc.org/articulo.oa?id=456061607007

Campoverde, Ronald., Rosero, Christian., González, Víctor. y Ortíz, Elías. (2018). Estilos de liderazgo de hombres y mujeres universitarios que estudian ciencias administrativas. Revista Espacios, 39(13), 7-15. Recuperado de https://www.revistaespacios.com/a18v39n13/a18v39n13p07.pdf

Casarejos, Fabrisio., Morten, Laura., y Nogueira, Mauricio (2017). Higher Education Institutions in the United States: Commitment and coherency to sustainability vis-à-vis dimensions of the institutional environment. Journal of Cleaner Production, 159(15), 74-84. DOI: https://doi.org/10.1016/j.jclepro.2017.05.034

Consorcio Mexicano de Instituciones de Educación Superior para la Sustentabilidad (COMPLEXUS). (2013). Indicadores para Medir la Contribución de las Instituciones de Educación Superior a la Sustentabilidad. Guanajuato: Universidad de Guanajuato.

Conferencia de Rectores de las Universidades Españolas (CRUE). (2018). Diagnóstico de la sostenibilidad ambiental en las Universidades españolas. Informe 2017. España: CRUE.

Fabre, Guadalupe. (2005). Las funciones sustantivas de la universidad y su articulación en un departamento docente. $V$ Congreso Internacional Virtual de Educación. Cuba: Universidad Agraria de La Habana. Recuperado de http://sedici.unlp.edu.ar/handle/10915/24694

Figueroa, Alma, Gilio, María., y Gutiérrez, Victoria. (2008). La función docente en la universidad. REDIE. Revista Electrónica de Investigación Educativa, 10, 1-14. Recuperado de https://redie.uabc.mx/index.php/redie/article/view/202

Fihlo, Walter. (2011). About the Role of Universities and Their Contribution to Sustainable Development. Higher Education Policy, 24, 427-438. DOI https://doi.org/10.1057/hep.2011.16

Filho, Walter., Shiel, Chris., Paço, Arminda., Mifsud, Mark., Veiga, Lucas., Londero, Luciana., Molthan-Hil, Petra., Pace, Paul., Azeiteiro, Ulises., Ruíz, Valeria., Caeiro, Sandra. (2019). Sustainable Development Goals and sustainability teaching at universities: Falling behind or getting ahead of the pack? Journal of Cleaner Production, 232, 285-294. DOI: https://doi.org/10.1016/j.jclepro.2019.05.309

González, Rosa. y Ochoa, Sergio. (2016). Cultura organizacional y desempeño en instituciones de educación superior: implicaciones en las funciones sustantivas de formación, investigación y extensión. Universidad \& Empresa, 18(30), 13-31. DOI https://doi.org/10.12804/rev.univ.empresa.30.2016.01 
Gutiérrez-Barba, Blanca., y Martínez-Rodríguez, María. (2010). El plan de acción para el desarrollo sustentable en las instituciones de educación superior. Escenarios posibles. Revista de la educación superior, 39(154), 111-132. Recuperado de http://www.scielo.org.mx/scielo.php?script=sci arttext\&pid=S0185$\underline{27602010000200006}$

Guzmán, Cecilia. (2014). El proceso extensionista universitario como vía para la pertinencia en la formación del futuro profesional. Espamciencia, 5(1), 17-24. Recuperado de https://redib.org/Record/oai articulo2075213-el-proceso-extensionista-universitariocomo-v\%C3\%ADa-para-la-pertinencia-en-la-formaci\%C3\%B3n-del-futuro-profesional

Holm, Tove., Sammalisto, Kaisu. y Vourisalo, Timo. (2015). Education for sustainable development and quality assurance in universities in China and the Nordic countries: a comparative study. Journal of Cleaner Production, 107, 529-537. DOI https://doi.org/10.1016/j.jclepro.2014.01.074

Kaviti, Josephine., Currie, Paul., Smit, Suzanne. y Kovacic, Zora. (2020). Urban metabolism of the informal city: Probing and measuring the 'unmeasurable' to monitor Sustainable Development Goal 11 indicators. Ecological Indicators, 119. DOI https://doi.org/10.1016/j.ecolind.2020.106746

Lange, Amanda., Filho, Walter., Londero, Luciana. y Sapper, Juliane. (2019). Assessing research trends related to sustainable development Goals: Local and global issues. Journal of Cleaner Prod, 208, 841-849. DOI https://doi.org/10.1016/i.jclepro.2018.09.242

Lozano, Rodrigo., Ceulemans, Kim., Alonso-Almeida, Mar., Huisingh, Donald., Lozano, Francisco., Waas, Tom., Lambrechts,Wim., Lukman, Rebeka. y Hugé, Jean. (2015). A review of commitment and implementation of sustainable development in higher education: results from a worldwide survey. Journal of Cleaner Production, 108, 1-18. DOI https://doi.org/10.1016/j.jclepro.2014.09.048

Martínez, Cynthia. y González-Gaudiano, Edgar. (2015). Las políticas para la sustentabilidad de las Instituciones de Educación Superior en México: entre el debate y la acción. Revista de la Educación Superior, 44(174), 61-74. DOI https://doi.org/10.1016/j.resu.2015.06.002

Martínez-Campillo, Almudena. and Fernández-Santos, Yolanda (2020). The impact of the economic crisis on the (in)efficiency of public Higher Education institutions in Southern Europe: The case of Spanish universities. Socio-Economic Planning Sciences, 71. DOI https://doi.org/10.1016/i.seps.2019.100771

Mohamed, Omer. y Noguchi, Takafumi. (2019). A conceptual framework for understanding the contribution of building materials in the achievement of Sustainable Development Goals $\begin{array}{lllll}\text { (SDGs). Sustainable Cities and Society, } & \text { 52, }\end{array}$ https://doi.org/10.1016/j.scs.2019.101869

Organización para la Cooperación y el Desarrollo Económico (OECD). (2019). Higher Education in Mexico: Labour Market Relevance and Outcomes. Recuperado de https://www.oecd.org/fr/publications/higher-education-in-mexico-9789264309432en.htm 
Organización de las Naciones Unidas (ONU). (2015). Objetivos de Desarrollo Sostenible. Recuperado de https://www.un.org/sustainabledevelopment/es/

Pacheco-Blanco, Bélgica. y Bastante-Ceca, María. (2016). Green public procurement as an initiative for sustainable consumption. An exploratory study of Spanish public universities. Journal of cleaner production, 133, 648-656. DOI: https://doi.org/10.1016/i.jclepro.2016.05.056

Programa de las Naciones Unidas para el Desarrollo (PNUD) (2020). Antecedentes PNUD. Recuperado de https://cutt.ly/GWt1lqR

Sáenz, Orlando. (2017). Primera década de la Alianza de Redes Iberoamericanas de Universidades por la Sustentabilidad y el Ambiente. Educación Superior y Sociedad, 28, 37-64.

Recuperado

https://www.iesalc.unesco.org/ess/index.php/ess3/article/view/83/80

Sustainable Development Solutions Network (SDSN). (2017). Getting started with the SDGs in universities: A guide for universities, higher education institutions, and the academic sector. Melbourne: Sustainable Development Solutions Network - Australia/Pacific. Recuperado de http://ap-unsdsn.org/wp-content/uploads/University-SDGGuide web.pdf

Secretaria de Educación Pública (SEP). (15 de 01 de 2020). Sistema de Captura del Formato 911. Recuperado de http://www.f911.sep.gob.mx/2018-2019/Login.aspx

UII, M., Martínez, María., Pinero, A. y Aznar, Pilar. (2010). Análisis de la introducción de la sostenibilidad en la enseñanza superior en Europa: compromisos institucionales y propuestas curriculares. Revista Eureka Sobre Enseñanza y Divulgación de las Ciencias, 7, 413-432. Recuperado de https://www.redalyc.org/articulo.oa?id=92013009020

United Nations Enviroment Programme (UNEP). (2014). Greening Universities Toolkit V2.0. Transforming universities into green and sustainable Campuses: A Toolkit for implementers. United Nations Environment Programme. Recuperado de https://cutt.ly/FWt1QdU

Organización de las Naciones Unidas para la Educación, la Ciencia y la Cultura (UNESCO). (1998). La educación superior en el siglo XXI. Visión y acción. París: UNESCO. Recuperado de http://publicaciones.Anuies.mx/revista/107/1/4/es/declaracion-mundialsobre-la-educacion-superior-en-el-siglo-xxi

Vallaeys, François. (2006). Responsabilidad social universitaria: marco conceptual, antecedentes, herramientas. Lima: Banco Interamericano de Desarrollo.

Wright, Tarah. (2002). Definitions and frameworks for environmental sustainability in higher education. International Journal of Sustainability in Higher Education, 15, 105-120. DOI https://doi.org/10.1016/S0952-8733(02)00002-8

Zapata-González, Lina., Quinceno-Hoyos, Andrés., y Tabares-Hidalgo, Luisa. (2016). Campus universitario sustentable. Revista de Arquitectura, 18(2), 107-119. DOI http://dx.doi.org/10.14718/RevArq.2016.18.2.10 


\section{Revista indizada en}
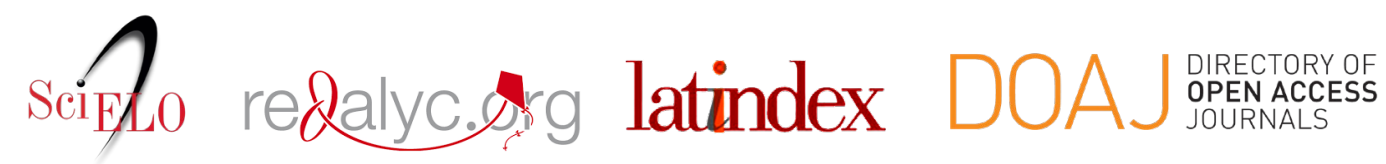

Distribuida en las bases de datos:

- Dialnet
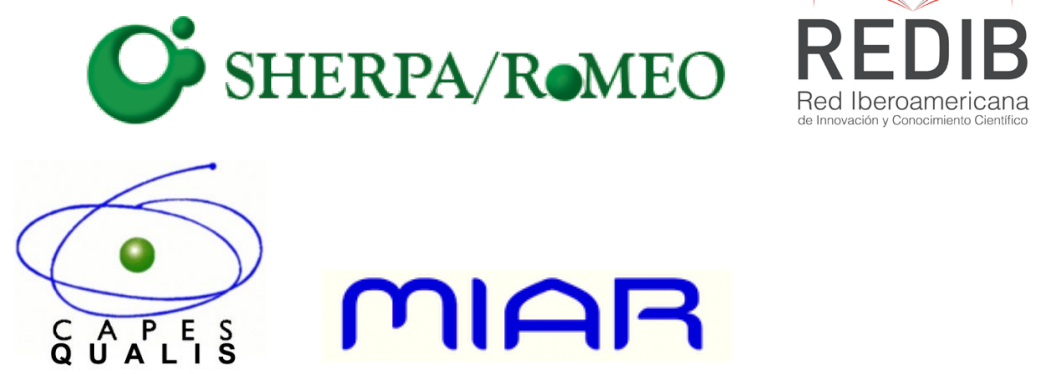

MIAR 